Research Article

\title{
Identification of Three-Dimensional Equivalent Material Properties for Laminated Disks Pack of Electric Machine Stators: Application in Reciprocal Compressors
}

\author{
Jean C. Marcon, ${ }^{1}$ Olavo M. Silva, ${ }^{1}$ Thiago A. Fiorentin ${ }^{D},{ }^{2}$ and Arcanjo Lenzi ${ }^{1}$ \\ ${ }^{1}$ Mechanical Engineer Department, Federal University of Santa Catarina, Florianópolis, Brazil \\ ${ }^{2}$ Mobility Engineer Department, Federal University of Santa Catarina, Joinville, Brazil
}

Correspondence should be addressed to Thiago A. Fiorentin; thiago_antonio@hotmail.com

Received 27 December 2018; Revised 31 March 2019; Accepted 18 April 2019; Published 27 May 2019

Academic Editor: Jussi Sopanen

Copyright (c) 2019 Jean C. Marcon et al. This is an open access article distributed under the Creative Commons Attribution License, which permits unrestricted use, distribution, and reproduction in any medium, provided the original work is properly cited.

\begin{abstract}
Laminated structures can be represented computationally by the finite element method (FEM) using the homogenization procedure, which consists of the adjustment of equivalent orthotropic properties to a homogeneous structure. The application occurs in stators of electric machines composed of stacked laminated disks connected to each other through windings and other fastening components. This paper describes a method to the dynamic characterization of a typical laminated stator through the application of the homogenization technique to the magnetic core and consideration of the effect of winding contour conditions and screw joints. Two simplified three-dimensional models for the stator were compared. The first considers the application of a typical tightening of the fastening screws and the presence of a homogeneous isotropic volume representing the winding. The second considers the effect of the boundary condition of the winding on the region of the teeth of the nucleus in order to reduce the degrees of freedom of the complete model. The coupling between the components is accomplished through the application of modal synthesis methods, which require the definition of the surfaces and the type of connection between the components. The obtainment of the set of equivalent orthotropic properties is based on the minimization of residues related to the difference between the natural and experimental frequencies in the range of 0 to $10 \mathrm{kHz}$. This was carried out using the multiobjective genetic algorithm (MOGA) method used in conjunction with commercial Ansys ${ }^{\circledR}$ software. Both models presented satisfactory experimental correlation. The simplified model demonstrated limitations of representativeness emphasized in specific frequency bands.
\end{abstract}

\section{Introduction}

Laminated structures such as the stator of an electric motor (Figure 1) need to be analyzed dynamically in the design phase, preceding industrial application. Modeling complex structures like this can be difficult in the case of unfamiliarity of the mounting properties.

It is impracticable to create a model with the FEM approach considering all the laminated disks, winding, and contacts between the components, mainly for industrial application purposes. The number of degrees of freedom would be very high, requiring excessive and costly processing capacity $[1-3]$.
On the other hand, the more the structural details are included in the modeling, especially for small-sized and medium-sized engines, the more the representative tends to be the model [4]. Thus, as the computational capacity increases, more details can be considered.

The set of existing techniques, also known as homogenization methods, have been used to recreate the behavior of a heterogeneous structure, reducing the multiplicity of the properties of its components and the number of degrees of freedom of the numerical model. These methods consider the homogenization technique through the substitution of a heterogeneous structure (Figure 2(a)) with another continuous equivalent (Figure 2(b)), in which one 

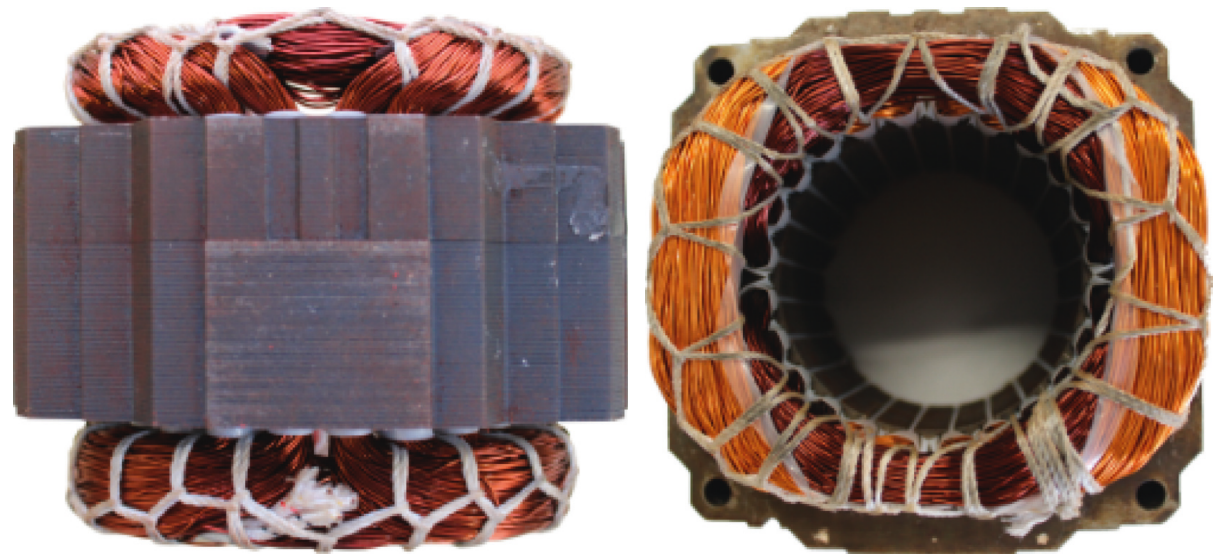

FIGURE 1: Stator and winding.

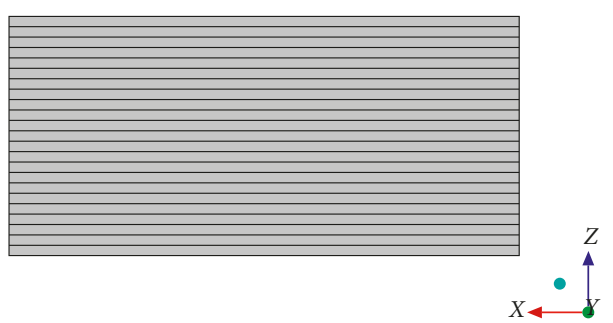

(a)

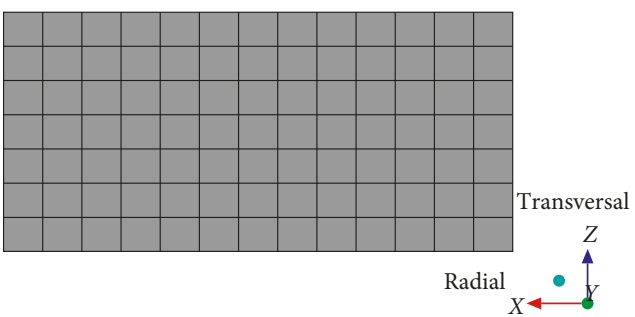

(b)

Figure 2: Principle of homogenization: (a) set of stacked disks; (b) mesh that represent the homogeneous volume of the disks.

can define properties for the approximate representation of the dynamic behavior of the original structure $[5,6]$. For the three-dimensional case (3D), their application has proved to be satisfactory in the modeling of composite materials $[5,7,8]$ and laminated stators $[6,9]$.

Laminated structures of electric motors are being studied for the understanding of their dynamic behavior and potential representations through FEM [4, 10-13]. In addition to the need for a more in-depth understanding of the behavior of stators of electrical machines, few works are focused on the use of 3D homogenization methods to better represent them. Moreover, the determination of elastic properties is restricted to specific applications, often not applying to the FEM $[7,14]$.

Studies were not found in the literature dealing with methods to identify equivalent orthotropic properties for this type of structure, considering prestress effects due to the physical presence of fastening elements coupled to the blade pack. The identification of equivalent isotropic properties for the winding (without fixation resin) in conjunction with the simultaneous identification of orthotropic properties for the package of laminated disks is also an approach not found in the literature.

This paper describes the alternative and practical homogenization method for the dynamic characterization of electric machine stators composed of connections for determination of equivalent $3 \mathrm{D}$ material properties. The stator of an electric motor, shown in Figure 1, was used in the development of this method. The application of the homogenization technique eliminates the need to represent the contacts between laminated disks and allows the use of larger finite elements, making the modeling feasible. The same is true for the volume occupied by the winding, which is connected to the stator teeth. This work is an extension of the research developed by the authors in the field of vibration of domestic refrigeration devices [15-17].

The correlation methods adopted in the model adjustment process and the linear stress-strain law taken into account in the process of determining the equivalent orthotropic properties of the laminated disks pack are presented.

\section{Correlation Methods}

Correlation methods applied to the model fitting take into account a numerical and experimental comparison between natural frequencies and frequency response functions (FRFs) [18]. For comparison of the $p$ pairs of numerical natural frequencies $\omega_{p}^{\mathrm{N}}$ and experimental frequencies $\omega_{p}^{\mathrm{E}}$, a relative difference can be quantitatively adopted, as given by

$$
\Delta \omega_{\mathrm{n}}\left(\omega_{p}^{\mathrm{N}}, \omega_{p}^{\mathrm{E}}\right)=\frac{\omega_{p}^{\mathrm{N}}-\omega_{p}^{\mathrm{E}}}{\omega_{p}^{\mathrm{E}}} .
$$

Another common way to correlate natural frequencies is to calculate the average $\overline{\Delta \omega_{n}}$, given by the simple average of the module of the individual deviations of the natural frequency pairs $p, N_{p}$ being the total number of pairs used in the comparison, as shown in 


$$
\overline{\Delta \omega_{\mathrm{n}}}=\frac{1}{N_{p}} \sum_{p=1}^{N_{p}}\left|\Delta \omega_{\mathrm{n}}\left(\omega_{p}^{\mathrm{N}}, \omega_{p}^{\mathrm{E}}\right)\right| .
$$

Allemang and Brown [19] recommended calculating an overall divergence $\ell_{\omega}$ between the pairs of natural frequencies, as indicated in

$$
\ell_{\omega}=\sqrt{\sum_{p=1}^{N_{p}} \frac{\left(\omega_{p}^{\mathrm{N}}-\omega_{p}^{\mathrm{E}}\right)^{2}}{\left(\omega_{p}^{\mathrm{E}}\right)^{2}}} .
$$

In addition, it is important to correlate the numerical and experimental modal forms corresponding to the natural frequencies selected for the adjustment through the modal assurance criterion (MAC), defined by the following equation $[19,20]$ :

$$
\operatorname{MAC}\left(\psi_{p}^{\mathrm{N}}, \psi_{p}^{\mathrm{E}}\right)=\frac{\left|\left\{\psi^{\mathrm{N}}\right\}_{p}^{\mathrm{T}}\left\{\psi^{\mathrm{E}}\right\}_{p}\right|^{2}}{\left\{\psi^{\mathrm{N}}\right\}_{p}^{\mathrm{T}}\left\{\psi^{\mathrm{N}}\right\}_{p}\left\{\psi^{\mathrm{E}}\right\}_{p}^{\mathrm{T}}\left\{\psi^{\mathrm{E}}\right\}_{p}} .
$$

For a pair $p$ of eigenvectors (numerical $\psi_{p}^{\mathrm{N}}$ and experimental $\psi_{p}^{\mathrm{E}}$ ), the closer this parameter is to unity, the stronger the correlation between the modal forms will be. In contrast, a value close to zero indicates a weak correlation. In general, a MAC value above 0.7 is satisfactory and, in the case of complex models, values over 0.6 are acceptable $[19,21]$.

It is also possible to calculate a mean modal assurance correlation $(\overline{\mathrm{MAC}})$, for a number of eigenvector pairs $N_{p}$, applying

$$
\overline{\mathrm{MAC}}=\frac{1}{N_{p}} \sum_{p=1}^{N_{p}} \operatorname{MAC}\left(\psi_{p}^{\mathrm{N}}, \psi_{p}^{\mathrm{E}}\right) .
$$

Iterative methods of updating models have been widely studied and applied to vibroacoustic systems. They are based on minimizing a norm calculated from a $\ell$ residual. This residual is usually dependent on the difference between pairs $p$ of numerical quantities $N$ and experimental quantities $E$ which, in general, is associated with the total mass (equation (6)) and the natural frequency (equation (7)), to the vibration modes, or the FRFs and the correlation coefficients between them; the latter three are not addressed in this work [22-28]. In equation (6), $m^{\mathrm{N}}$ and $m^{\mathrm{E}}$ are the masses of the numerical model and the physical piece, respectively. Comparing equations (1) and (7), it is noted that $\Delta \omega_{\mathrm{n}}$ can also be defined as a residue $\ell_{\omega_{p}}$ for the purpose of model fitting:

$$
\begin{array}{r}
\ell_{m}=m^{\mathrm{N}}-m^{\mathrm{E}}, \\
\left\{\ell_{\left.\omega_{p}\right\}}\right\}=\frac{\omega_{p}^{\mathrm{N}}-\omega_{p}^{\mathrm{E}}}{\omega_{p}^{\mathrm{E}}} .
\end{array}
$$

Each of the above residue relations has advantages depending on the accuracy required and the system to be fitting. In general, it is sufficient for the fit of a model to minimize the residues related to the natural frequencies and modal shapes. Already, the residue between masses can be reduced directly through the weighing of the physical piece.
Several iterative methods are found in the literature, which aim to minimize these residues. Among them, the method of least squares, genetic algorithms, and artificial neural network stand out. In this work, it was used the genetic algorithm described below.

\section{Genetic Algorithm Applied to Fit Models}

Evolutionary algorithms such as MOGA have been widely applied in the engineering area [29] due to the simplicity, effectiveness, and possibility of working with several types of input parameters, to be multiobjective and already available in commercial software, allowing the least involvement with the user [30,31].

A hybrid variant of the popular NSGA-II (nondominated sorted genetic algorithm-II) based on controlled elitism concepts [32] was applied in the fit process of the physical properties of the numerical models of this work, whose algorithm is implemented in the commercial software Ansys $^{\circledR}$.

In the model fitting process, the residuals of the natural frequencies $\ell_{\omega_{p}}$ are minimized using MOGA, the input parameters being related to the physical properties of the component material, for instance, the modulus of elasticity and the Poisson coefficient.

The first step is to perform an analysis, in which appropriate maximum and minimum values are defined for the properties to be adjusted. In this process, some numerical modal analyses are performed, starting from the approximate knowledge of the connection properties and of some individual components of the stator determined experimentally. It is sought to carry out variations on a restricted set of orthotropic properties (verify Section 4) starting from a typical profile for this type of laminated structure. Thus, a check can be made that the numerical modal shapes correspond to experimental modal shapes through the MAC and the natural frequencies can be selected for the fine fitting process.

In the MOGA, the total number of individuals of the initial population (set of properties) is defined, which will be randomly generated for the beginning of the analysis. The initial population of the input parameter is tested, and based on the results, the iterative process begins. In this step, there are combinations and mutations between the selected candidates and results closer to the goal are reached at each iteration. The minimization of the residuals between the numerical results and the reference experimental parameters (natural frequencies) occurs at each iteration until reaching convergence.

The stopping criterion is defined by the maximum allowable Pareto percentage, that is, it represents a percentage relation of the number of variables that reach a certain quality criterion at each iteration. Additionally, a convergence percentage is defined that seeks the stability of the population, based on the mean and standard deviation of the output parameters.

In this way, the numerical model was adjusted to represent the dynamic behavior of the stator. After adjusting the natural frequencies, the correlation of the 
modal shapes and the numerical and experimental FRFs was performed. Ansys ${ }^{\circledR}$ commercial software is used for the numerical solution of the dynamic problems presented.

\section{Stress-Strain Law}

In general, a solid body can have six possible stress $\{\sigma\}$ and strain $\{\varepsilon\}$ components. The simplest linear relationship between these components is of the form $\{\sigma\}=[C]\{\varepsilon\}$, where $[C]$ is an elastic matrix, $\{\sigma\}$ is the stress tensor, and $\{\varepsilon\}$ is the strain tensor. Thus, Hooke's law for anisotropic materials can be represented by equation (8), which presents 21 independent elastic constants $C_{i j}[33,34]$ :

$$
\left\{\begin{array}{c}
\sigma_{x} \\
\sigma_{y} \\
\sigma_{z} \\
\sigma_{y z} \\
\sigma_{z x} \\
\sigma_{x y}
\end{array}\right\}=\left[\begin{array}{ccc}
C_{11} & \cdots & C_{16} \\
\vdots & \ddots & \vdots \\
C_{61} & \cdots & C_{66}
\end{array}\right]\left\{\begin{array}{c}
\varepsilon_{x} \\
\varepsilon_{y} \\
\varepsilon_{z} \\
\varepsilon_{y z} \\
\varepsilon_{z x} \\
\varepsilon_{x y}
\end{array}\right\} .
$$

In many practical problems, the materials have planes of symmetry along three orthogonal directions, which give them orthotropic properties. Thus, equation (8) can be simplified and the inverse of the elasticity matrix $[C]$ is given by the conformity matrix $[D]$, represented by

$$
[D]=\left[\begin{array}{cccccc}
\frac{1}{E_{x}} & \frac{-v_{x y}}{E_{x}} & \frac{-v_{z x}}{E_{z}} & 0 & 0 & 0 \\
\frac{-v_{x y}}{E_{x}} & \frac{1}{E_{y}} & \frac{-v_{y z}}{E_{y}} & 0 & 0 & 0 \\
\frac{-v_{z x}}{E_{z}} & \frac{-v_{y z}}{E_{y}} & \frac{1}{E_{z}} & 0 & 0 & 0 \\
0 & 0 & 0 & \frac{1}{2 G_{y z}} & 0 & 0 \\
0 & 0 & 0 & 0 & \frac{1}{2 G_{z x}} & 0 \\
0 & 0 & 0 & 0 & 0 & \frac{1}{2 G_{x y}}
\end{array}\right] \text {, }
$$

where $E_{i i}$ is Young's modulus in the main directions of the material; $G_{i j}$ is the shear modulus; and $v_{i j}$ is the Poisson ratio, which obeys the relations of

$$
v_{i j}=v_{j i} \frac{E_{i i}}{E_{j j}} .
$$

For isotropic materials, the properties do not vary with the orthogonal direction and are simply represented by $E, v$, and $G$ and the matrix $[D]$ can be simplified.
For each orthotropic elastic linear material, nine properties can be adjusted, notably the elastic moduli $E_{x}, E_{y}$, and $E_{z}$, the Poisson ratios $v_{x y}, v_{y z}$, and $v_{x z}$, and shear moduli $G_{x y}, G_{y z}$, and $G_{x z}$. In the case of isotropic materials, the set of properties is restricted to $E, \nu$, and $G$.

At each iteration of the model adjustment process, some restrictions are imposed on the elastic constants of the orthotropic material. The first condition states that the elastic constants are positive, as indicated by

$$
E_{x}, E_{y}, E_{z}, G_{x y}, G_{y z}, G_{z x}>0 .
$$

The second considers that the determinant of the matrix [D] must also be positive, according to

$$
1-v_{x y} \nu_{y x}-v_{z x} \nu_{x z}-v_{y z} \nu_{z y}-2 v_{y x} v_{z y} \nu_{x z}>0 \text {. }
$$

Finally, the previous requirements lead to the relations of

$$
\begin{aligned}
& v_{y x}<\sqrt{\frac{E_{y}}{E_{x}}}, \\
& v_{z y}<\sqrt{\frac{E_{z}}{E_{y}}}, \\
& v_{x z}<\sqrt{\frac{E_{x}}{E_{z}}} .
\end{aligned}
$$

Section 5 describes the experimental procedure used for the determination of the modal parameters of the electric motor stator and the dynamic characterization of the laminated disks of which it is comprised.

\section{Experimental Procedure}

In order to reduce the number of variables in the stator model adjustment process, seven laminated disks were characterized to evaluate the feasibility of fixing the modulus of elasticity in the two directions of the radial plane and the respective Poisson coefficient. In this procedure, the laminated disks were hung in the support represented in Figure 3 and impacted by a hammer at the response measurement point. Through the FRFs obtained by the fixation of a uniaxial accelerometer of negligible mass, one can analyze the manufacturing variability between the laminated disks and adjust the numerical model to estimate their equivalent properties.

The configuration used in the experimental modal analysis of the full stator is shown in Figures 4(a) and 4(b). Figure 4(a) shows the shaker connection with the stator for the application of excitement using white noise in the radial direction of the component. The white noise type was adopted by observing better coherence between excitation and response and by providing good results for this type of application in the investigated literature [4, 10, 35]. The signal was generated only at frequencies above $70 \mathrm{~Hz}$. To maintain stability and low noise and distortion, the applied force was maintained at adequate levels throughout the frequency range considered in the analysis [36]. The connection is made through the stinger, the force signals are 


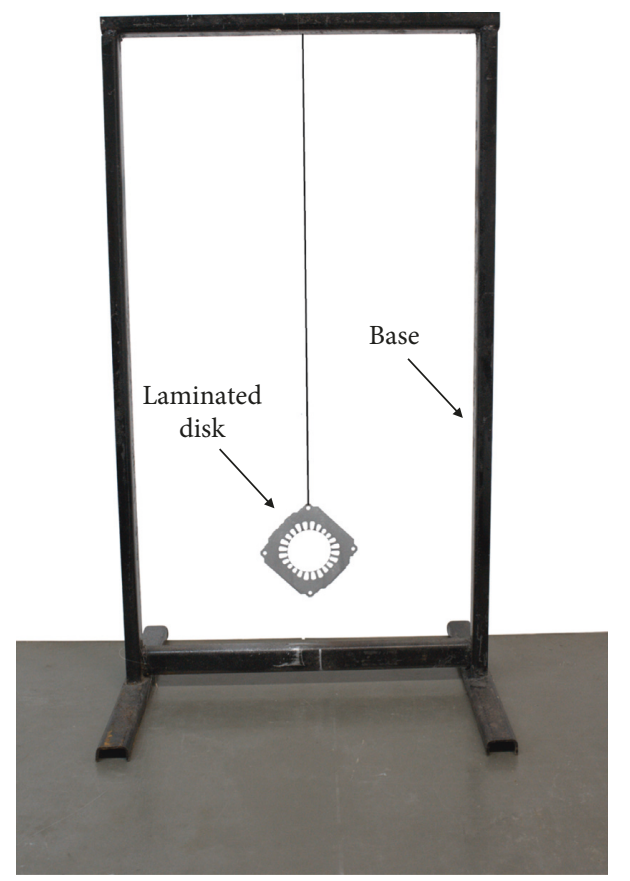

Figure 3: Experimental setup used for laminated disk analysis.

measured by the load cell, and the acceleration signals are measured with triaxial accelerometers at 50 points, as indicated in Figure 4(c). A second transverse excitation was adopted as a reference, as shown in Figure 4(b). The stator was suspended by a support of high mass and stiffness so as not to interfere with the measurement results.

It was verified excellent repeatability of the tests performed with the stator, always following a standard assembly procedure. Also, in a reproducibility test associated with the experimental setup and the operator, a stator was assembled and disassembled seven times and FRFs were obtained at point E1 (verify Figure 4(c)), for the transverse excitation reference. As shown in Figure 6, the experimental setup cannot be accurately reproduced due to minor alignment and gluing changes of the transducers. It is perceived that the 5 to $10 \mathrm{kHz}$ band is the most sensitive.

A simplified modal analysis was performed with a PSV500 scanning vibrometer, considering only two orthogonal planes of the stator, in order to improve the definition of modal shapes of the winding, mainly between 300 and $900 \mathrm{~Hz}$.

The scanning vibrometer has the principle of operation that favors accurate and localized measurements. From a laser beam incident on a surface of interest, it is possible to quantify the point speed of vibration in the direction of incidence. The region of the specified point occupies a small area, being advantageous the surface scanning of parts with reduced size and mass, and provides the possibility of creation and measurement of more refined meshes that facilitate the modal identification, overcoming the limitations of the use of accelerometers (mass and occupied area).

In contrast, measurements are performed in only one direction (1D). The absence of punctual information on the other two orthogonal axes may make analysis difficult in the case of the study of components in which the quantification of vibration is important at the three-dimensional (3D) level. Thus, the analyses performed with the stator were done carefully and complement the modal study with triaxial accelerometers.

As shown in Figure 7, the configuration of the experiment is like that of the previous modal analysis (Figure 4), except for the quantification of the response signals, which are processed by the PSV-500 vibrometer.

An example of an experimental mesh with 221 points is shown in Figure 8. The 89 blue points were defined for the measurement of winding response, whose instrumentation with accelerometers is not feasible. The mesh has a greater refinement providing good definitions of the modal shapes in the desired reference plane.

The numerical models presented in the next section were fitted using the modal parameters obtained experimentally. In this procedure, the concepts presented in Section 2-4 were applied.

\section{Computational Procedure}

In order to estimate the physical properties of the laminated disk and to associate them with the radial behavior of the stator, a model was proposed through the application of the finite element method, represented in Figure 9, for the direct correlation between the numerical and experimental FRFs (verify reference point at which the excitation is applied). In the numerical model, the laminated disk was considered as a homogeneous isotropic material. The properties were fitted to the same element (quadratic hexahedral) used in the laminated disks pack of the stator model. Only a small variation in the modulus of elasticity of the isotropic laminated disk was verified when a triangular linear element was adopted (case of Figure 9).

With the application of the homogenization technique, two stator models were based on a simplified geometry (solid body representing the set of overlapping laminated disks), which considers the contour condition of the screws and the winding. The two models can be seen in Figures 10 and 5(b). The first considers the set of laminated disks as a continuous structure, and the winding is represented by an equivalent volume, fixed between the teeth of the stator, approaching the practical condition. The second presents a simplification, considering the effect of the winding on the teeth of the magnetic core. In this case, distinct orthotropic properties are determined for the two parts of the magnetic core. The inertial effect (mass moment of inertia) of the winding was approximated by an increase in the density in the region of the stator teeth, and in the radial plane $(x-y)$ of the teeth, the stiffness effect was introduced through an increase in the stiffness. Consequently, the shear modulus also changed in the region of the teeth, in relation to the external region (Figure 5(b)).

The densities used in the model are adjusted from experimental data and the use of equation (14), which gives $\rho$ as a function of the total mass $m_{\text {tot }}$ and the total volume $V_{\text {tot }}$ of the components: 


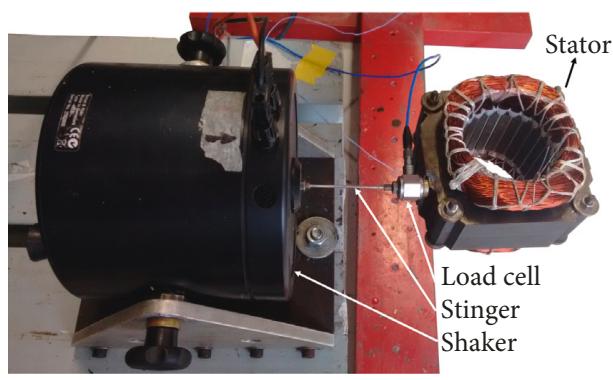

(a)

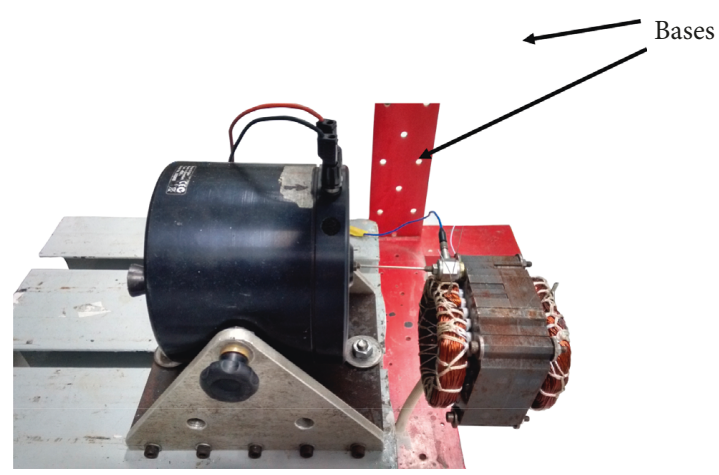

(b)

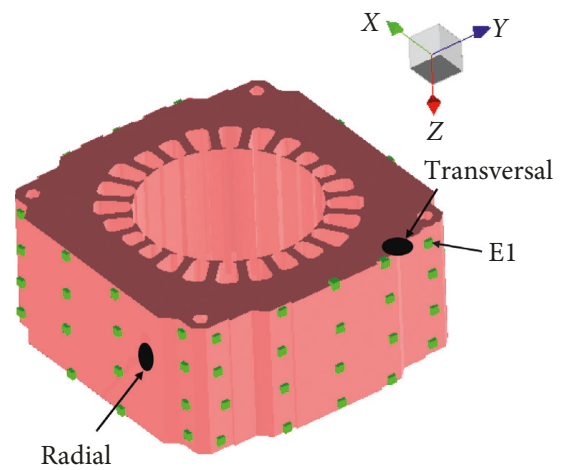

(c)

Figure 4: Experimental setup for modal analysis of the stator: (a) excitation in the radial direction ( $y$ direction); (b) excitation in the transversal direction ( $z$ direction); (c) experimental mesh with 50 points.

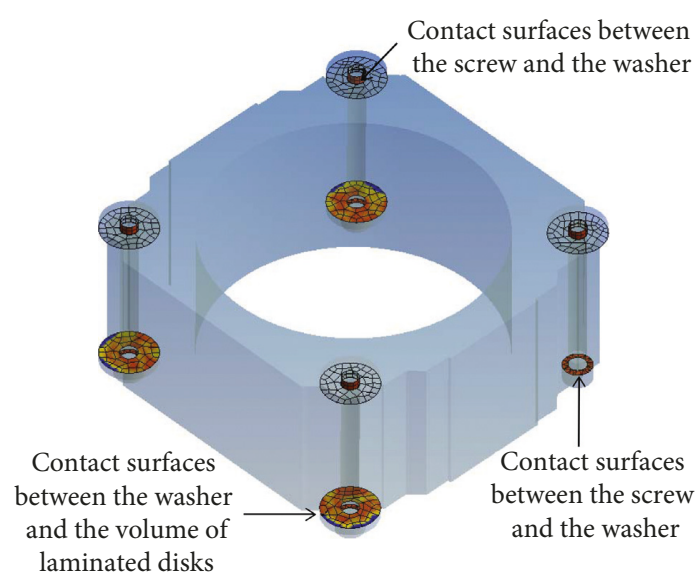

(a)

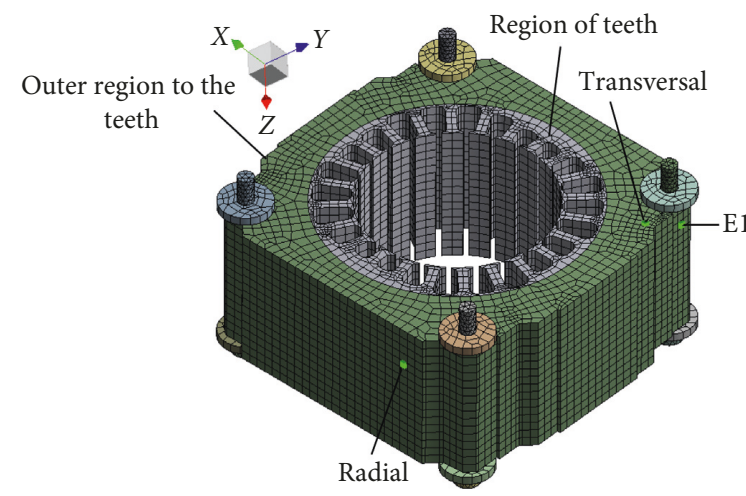

(b)

Figure 5: (a) Specification of contact regions between stator components for both models and (b) simplified numerical stator model.

$$
\rho=\frac{m_{\text {tot }}}{V_{\text {tot }}}
$$

In both numerical models, a quadratic hexahedral element was used to represent the equivalent volume of the laminated disks. In the complete model, the winding was represented with a quadratic tetrahedral element. The connections of the components of both models (washers and screws) were considered to have typical isotropic properties, with quadratic hexahedral elements. In addition, the number of nodes of each component is summarized in Table 1.
The contact interfaces between the components of both models are shown in Figure 5(a). The lower degree of contact between the washer and the screw was defined as bonded, with an augmented Lagrange formulation. To simplify the connection between the nut, the washer, and the bolt, the nut was omitted. The screw was connected directly to the washer by a bonded connection, defined as a multipoint constraint (MPC). The contact between the surfaces of the washer and the laminated disks pack was defined as frictional; that is, it is considered that there is a friction effect at this interface (as in practice). The coefficient of friction is defined according to 


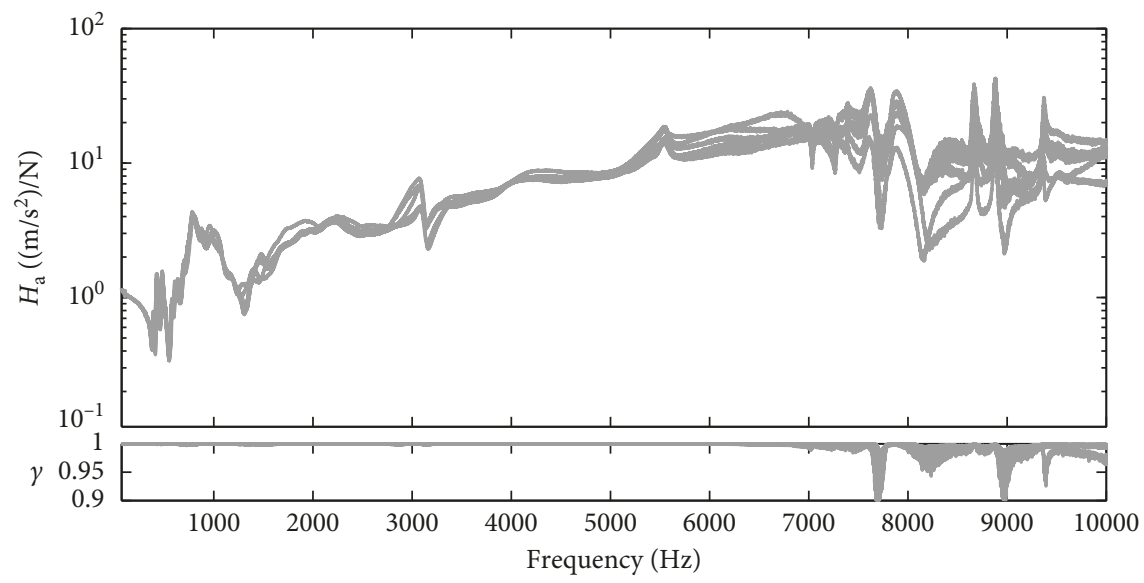

FIgURE 6: Assembly reproducibility analysis from seven experimental FRFs for transversal excitation ( $z$ direction) and response measurement at point E1 ( $z$ direction).

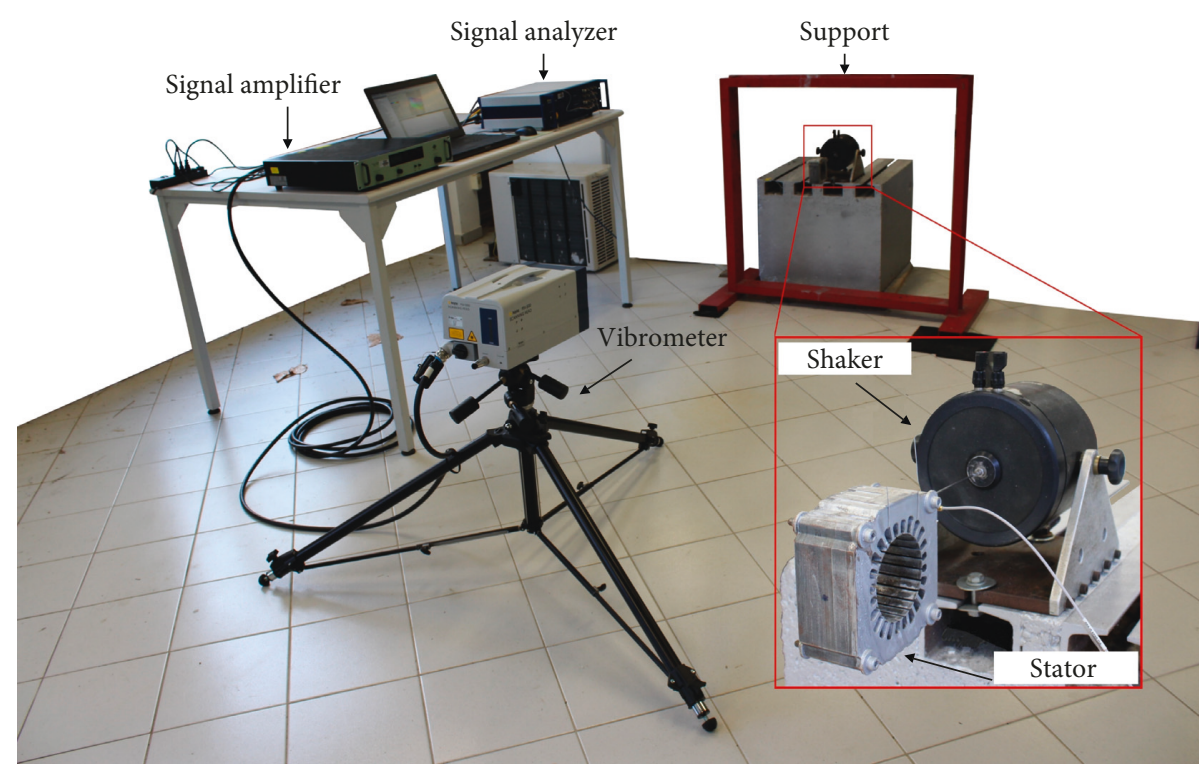

FIGURE 7: Experimental configuration used in unidirectional modal analysis.

empirical data (value of 0.15), and it is dependent on the physical conditions of the surfaces in contact.

Although not indicated in Figure 5(a), the augmented Lagrange formulation was used for the connection between the winding and the stator teeth, in the case of the complete model. These formulations provide greater sensitivity in adjusting the stiffness of the connection.

Since the modal and harmonic analyses are linear, the nonlinear connections used in the models (augmented Lagrange and frictional) underwent a linear adaptation. The reference and response points can be seen in Figure 5(b), resembling the experimental setup shown in Figure 4(c).

The stress-stiffening effect is included in a static analysis that precedes the modal analysis, making an initial estimation of the properties and applying a nominal prestress of $9.81 \mathrm{kN}$ on the screws. This prestress is the result of the torque applied to the screws in the standard experiment.

The modal analysis of the set is carried out with the prestress history and the application of modal synthesis methods [37-40]. These methods provide good modal analysis estimates of several interconnected components, including their connection properties.

\section{Results and Discussion}

The results related to the study of the laminated disk and the stator are presented, which supported the determination of the tridimensional properties of the numerical models. Finally, the results are compared.

7.1. Study of the Laminated Disk. The first model adjusted was that of the laminated disks. With the aid of the genetic algorithm, the first eight peaks of the numerical FRF were approximated to the equivalents of the average experimental FRF, using as the convergence criterion a limit value for the sum of the relative difference. A comparison between the FRFs can be observed in Figure 11. It is evident that the 


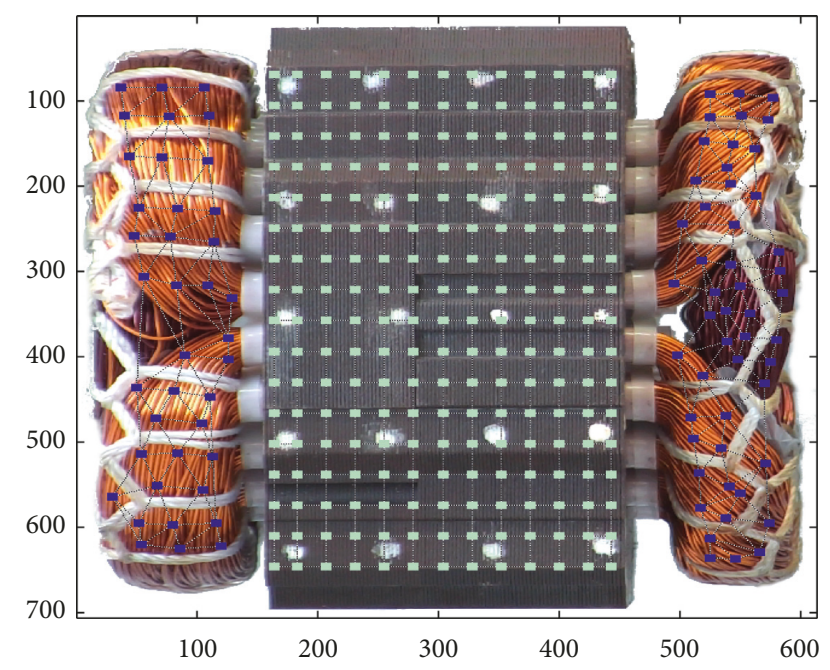

FIGURE 8: Experimental mesh used in unidirectional modal analysis of stator, including winding.

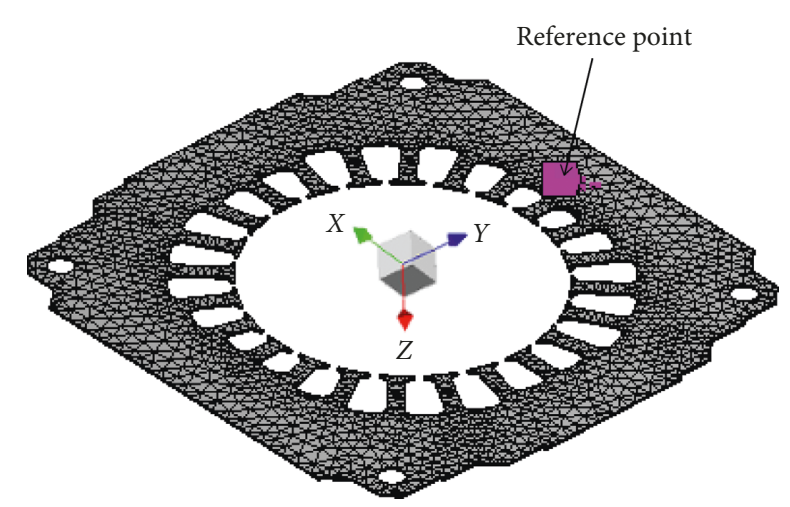

Figure 9: Numerical model of the laminated disk and reference point specification.

adjustment loses precision in terms of amplitude from $6 \mathrm{kHz}$ (influence of the experimental contour condition) and that the variation of the vibrational behavior due to the manufacturing is small (verify experimental FRFs in gray). The mass of the laminated disks was adjusted experimentally.

To obtain the optimal physical properties of the laminated disk (modulus of elasticity and Poisson coefficient), an initial population of 130 candidates, with 50 samples per iteration, was adopted in order to obtain satisfactory solutions for a total of 20 iterations. The final solutions were obtained after 516 evaluations and 10 iterations.

Table 2 shows the natural frequency values for the experimental and numerical reference FRFs, with the respective minimized relative errors. Both the average deviation of $2.8 \%$ and the overall divergence of $11.7 \%$ are satisfactory.

Wang [41] conducted an experimental study on the effects of the vibration between connected annular laminated disks for comparison with the results of the equivalent finite element model. He made vacuum coupling comparisons to investigate the effect of the thickness and the number of connected laminated disks, eliminating the effect

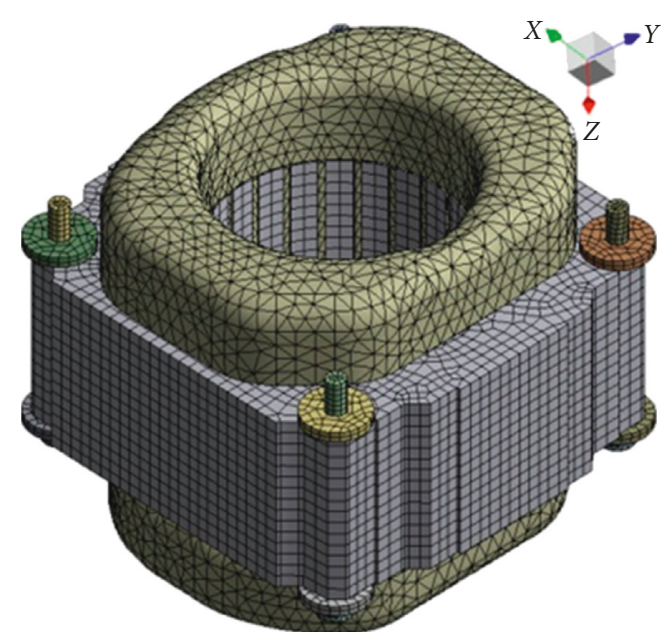

(a)

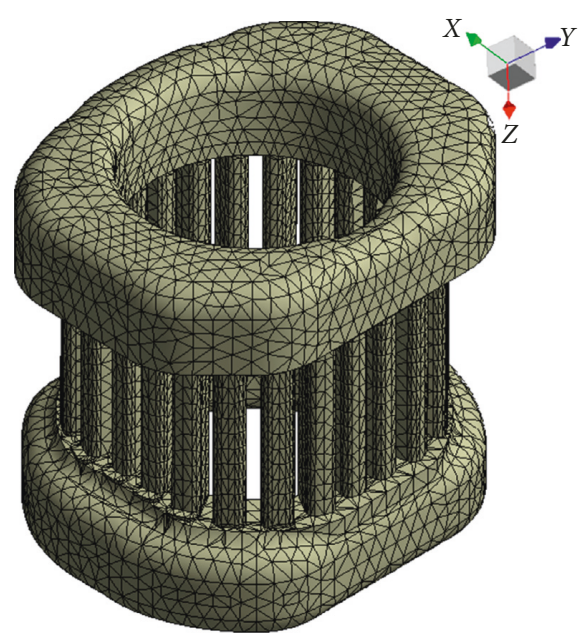

(b)

FIgURE 10: (a) Full numerical model of the stator, with the physical presence of the winding and (b) isotropic volume of the winding.

of the physical presence of the screws. It was found that the effects of the tightening and the number of laminated disks provide the transverse vibration modes more effectively when compared to the radial modal shapes, which is consistent with the results obtained herein. These effects are directly related to the damping and shearing of the laminated structure. The same author also identified the projection of the individual modes of a laminated disk on the overall modes of the set. Therefore, the first step in the verification of the dynamic behavior and adjustment of a numerical model of a stator should be the investigation of the laminated disk itself.

As Wang [41] observed, some modal shapes of a laminated disk may have characteristics very close to those identified in the case of multiple laminated disk coupling. Figure 12 shows some transversal and radial modal shapes of the laminated disk, numerically found, which are like those obtained experimentally with the stator. Although the transverse vibration modes (Figures 12(a)-12(c)) occur at very different frequencies, it can be noted that the radial vibration modes (Figures 12(d) and 12(e)) appear at 
TABLE 1: Approximate characteristics of the numerical model of the stator.

\begin{tabular}{lccc}
\hline Stator parts & Quantity & Element type & Number of nodes \\
\hline Equivalent volume of the laminated disks & 1 & Quadratic hexahedral & 97974 \\
Washers & 8 & Quadratic hexahedral & 2827 \\
Screws & 4 & Quadratic hexahedral & 11332 \\
\hline Equivalent volume of the winding & 1 & Quadratic tetrahedral & 126776 \\
\hline
\end{tabular}

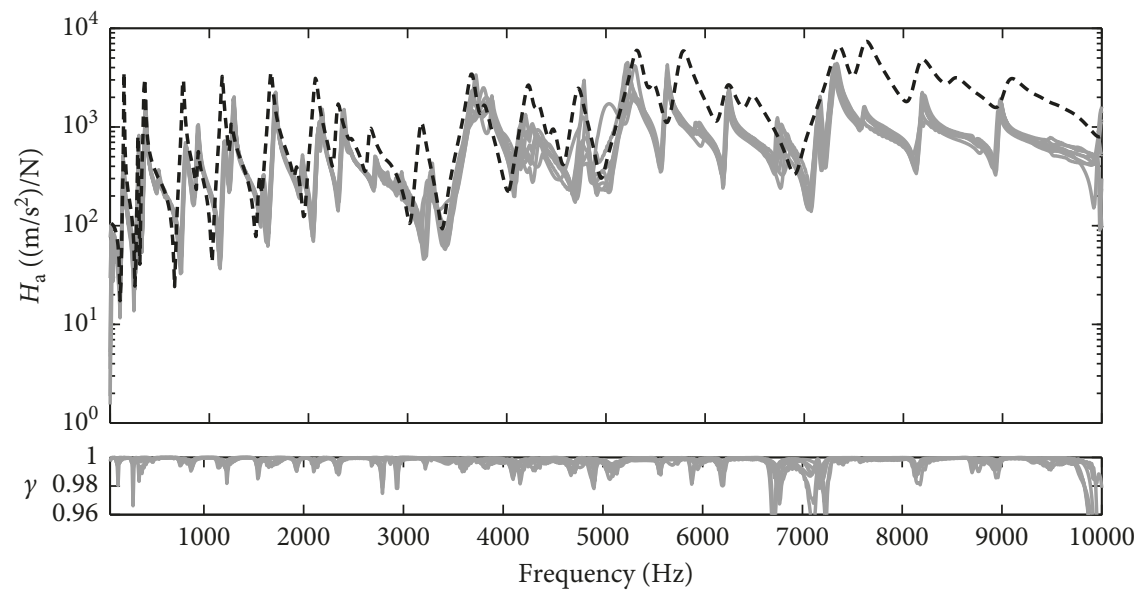

FIGURE 11: Numerical model of the laminated disk set in black (dashed line) and the experimental FRFs in gray (continuous line) as a reference.

TABle 2: Comparison between the numerical and experimental natural frequencies of the first eight peaks of the reference point FRF after the adjustment of the laminated disk model.

\begin{tabular}{lccc}
\hline Order & $\omega^{\mathrm{E}}(\mathrm{Hz})$ & $\omega^{\mathrm{N}}(\mathrm{Hz})$ & $\Delta \omega_{\mathrm{n}}(\%)$ \\
\hline 1 & 129.9 & 116.8 & -10.2 \\
2 & 290.2 & 280.3 & -3.4 \\
3 & 360.3 & 345.3 & -4.1 \\
4 & 490.0 & 487.4 & -0.5 \\
5 & 769.6 & 773.6 & 0.5 \\
6 & 890.3 & 882.8 & -0.8 \\
7 & 1160.5 & 1172.1 & 1.0 \\
8 & 1240.0 & 1218.0 & -1.8 \\
\hline Average (\%) & & & 2.8 \\
$\ell_{\omega}(\%)$ & & & 11.7 \\
\hline
\end{tabular}

frequencies very close to those corresponding to the set of stator laminated disks. These modal shapes should be observed on the stator after the model adjustment.

Due to the proximity of the modal characteristics, the isotropic properties adjusted for the laminated disk were used in the radial plane $(x-y)$ of the laminated disks pack of the complete stator model $\left(E_{x}, E_{y}, v_{x y}\right.$, and $\left.\rho\right)$ and in the region external to the teeth of the simplified model. Thus, in addition to the density, which can be adjusted directly with the weight, the fixed adjustment parameters include the Poisson coefficient and the modulus of elasticity in the radial plane. This simplification eliminates the need to represent the contact between the laminated disks and allows the use of larger finite elements, enabling the modeling. Another benefit is a reduction of the number of variables to be estimated in the adjustment and optimization of the numerical model.
7.2. Study of Stator. In Figure 13, observing the sum of the FRFs of the left lateral plane $(x-z)$, it is noted that the presence of winding dampens the structure response and small peaks arise at frequencies lower than $1000 \mathrm{~Hz}$. The structural responses corresponding to the peaks of the band 70 to $1000 \mathrm{~Hz}$ are shown in Figures 14(a)-14(c). These evidence the dominant deformations of the windings. This is because the mass of the teeth prevails in the upper and lower portions of the part and is connected with some rigidity between the teeth. The frequency of $819.3 \mathrm{~Hz}$ (Figure 14(b)) corresponds to the reciprocal modal shape in the frontal plane of the stator.

A damping addition is observed in the region of the main radial modal shapes, between the frequencies of 3000 and $4500 \mathrm{~Hz}$. From the characterization point of view, this energy dissipation makes it difficult to identify modal shapes and the model fit itself.

Carefully observing Figure 15, it is evident that when the analysis plane is changed, that is, when the left side view $(x-z$ plane $)$ is changed from the frontal view $(y-z$ plane), the sum of the mobilities differs considerably in frequencies below $1000 \mathrm{~Hz}$. Distinct peaks are evident between the results of the two planes, but the modal shapes are similar to those shown in Figure 14. This can be explained due to the asymmetry of mass distribution and stiffness of the winding along the structure, as shown in Figure 1.

Figure 16 shows that the amplitude of the peaks caused by the windings is considerably lower than the rest of the band, in frequencies between 1 and $10 \mathrm{kHz}$. This evidence shows that they are less participatory in the dynamic response of the set. 


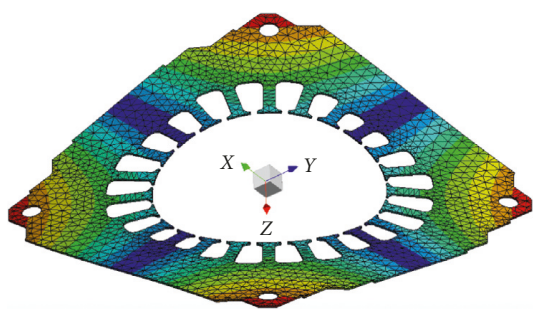

(a)

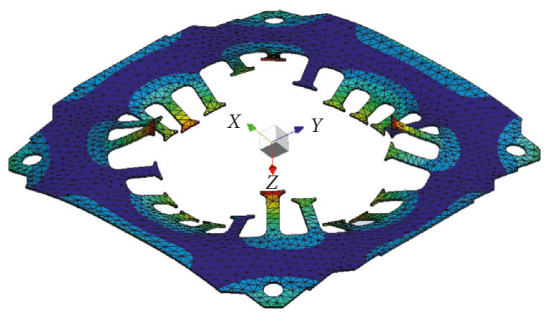

(c)

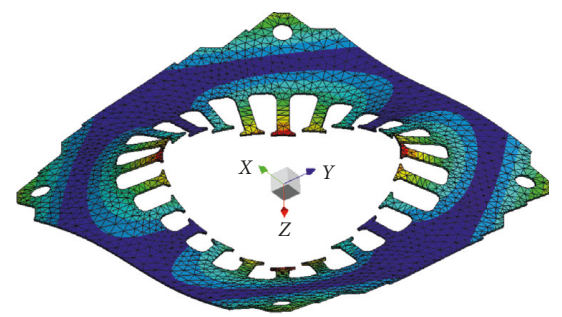

(b)

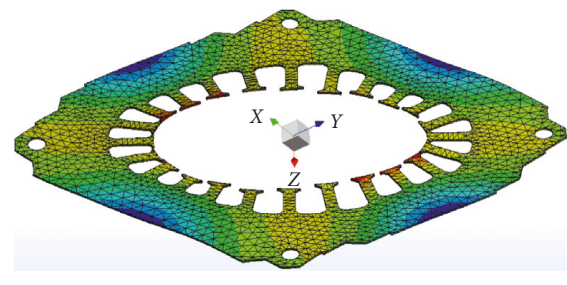

(d)

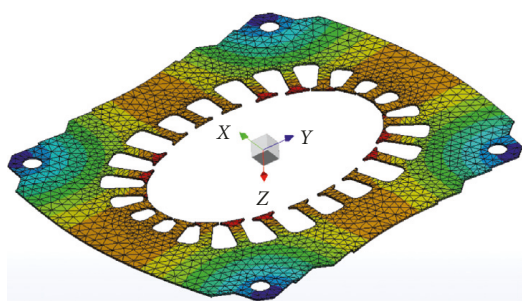

(e)

Figure 12: Numerical modal shapes of the laminated disk, whose characteristics are repeated on the stator laminated disks pack, according to experimental modal analysis: (a) $\omega^{\mathrm{N}}: 116.8 \mathrm{~Hz}$; (b) $\omega^{\mathrm{N}}: 773.6 \mathrm{~Hz}$; (c) $\omega^{\mathrm{N}}: 1509.3 \mathrm{~Hz}$; (d) $\omega^{\mathrm{N}}: 3769.8 \mathrm{~Hz} ;(\mathrm{e}) \omega^{\mathrm{N}}: 3986.2 \mathrm{~Hz}$.

7.3. Three-Dimensional Equivalent Material Properties. In order to be as faithful as possible to the physical constitution, each component of the stator was characterized separately. The washers, screws, and laminated disks were characterized and then added to the volume representing the set of laminated disks. The 3D homogenization technique was also used to represent the copper coil through a homogeneous volume with equivalent isotropic properties.

The isotropic properties $(E, \nu)$ for the winding were adjusted following the experimental references of the vibrometer, starting from information obtained in the literature, together with the adjustment of the orthotropic properties to the equivalent volume of the disks. In the case of the set of disks, only modal shapes common to both models were used. Due to the uncertainties related to the measurement limitations and, consequently, to the identification of modal experimental parameters, no emphasis was placed on the winding adjustment process. A deviation between natural frequencies of up to $20 \%$ was observed in relation to experimental references (Figures 17(e) and 17(f)). The connection properties between the components were kept unchanged throughout the process.

After an initial evaluation and the restriction of the lateral limits of the properties (minimum and maximum) within a range of suitable values according to Table 3 , the complete stator model (Figure 10(a)) was adjusted based on five experimentally identified modal shapes. According to Table 4, the relative maximum and minimum differences

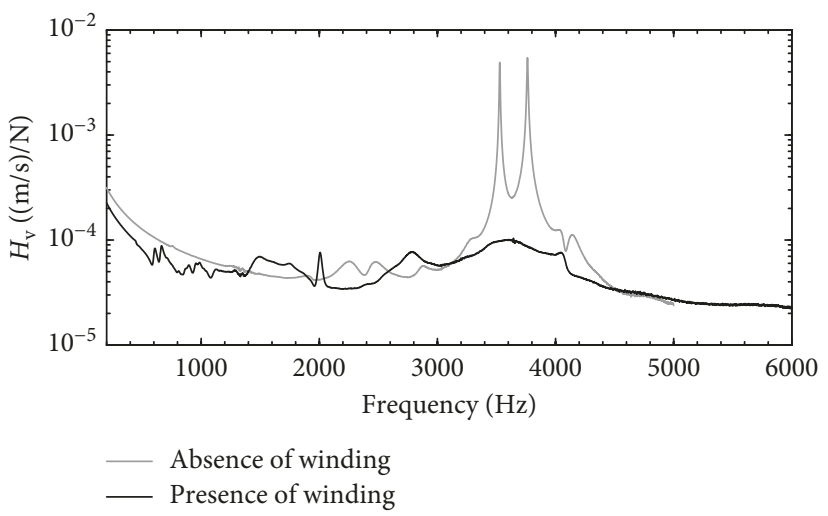

FIGURE 13: Influence of the winding for the case of radial excitation ( $y$ direction) and measurement of response in the same direction.

between the numerical and experimental natural frequencies were $-5.5 \%$ and $0.9 \%$, respectively. The overall divergence is $7.8 \%$, and the average is $2.9 \%$. The set of fitted properties are shown in Table 5.

The damping factor $\eta_{\mathrm{eq}}$ (Table 5) was adjusted after matching with the numerical and experimental FRFs, and its value is consistent with the results obtained experimentally. It should be noted that there may be other sets of parameters that represent the stator satisfactorily.

The natural frequencies that are most sensitive to the transversal shear moduli are related to the transverse modal shapes and shear modal shapes in the radial plane. The 


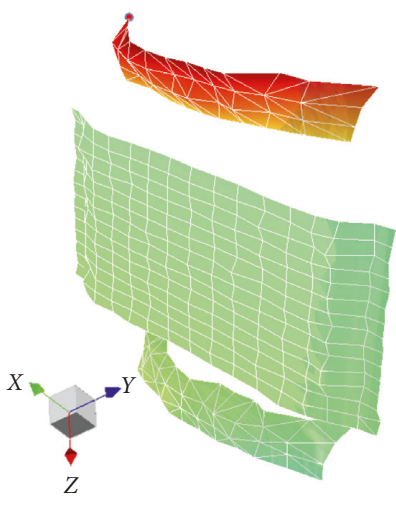

(a)

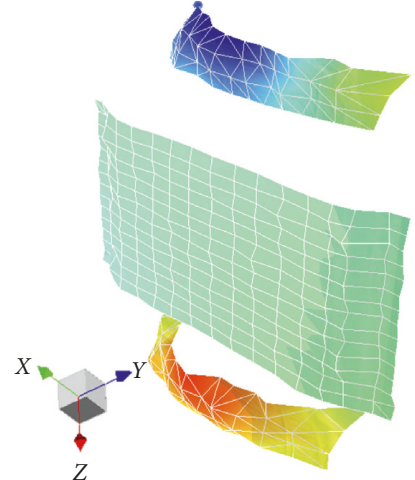

(b)

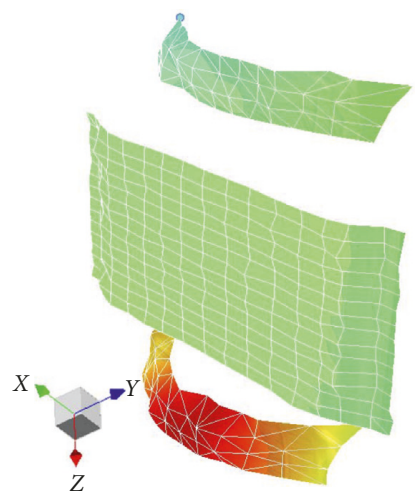

(c)

Figure 14: Experimental modal shapes of the winding for frequencies below $1000 \mathrm{~Hz}$ : (a) $\omega^{\mathrm{E}}: 616.9 \mathrm{~Hz}$; (b) $\omega^{\mathrm{E}}: 728.3 \mathrm{~Hz}(x-z$ plane) and $819.3 \mathrm{~Hz}\left(y-z\right.$ plane); (c) $\omega^{\mathrm{E}}: 793.9 \mathrm{~Hz}$.

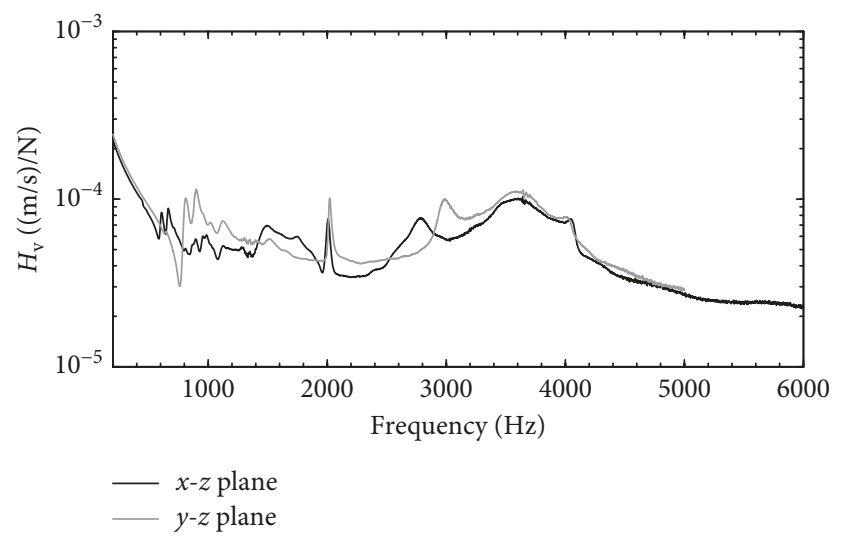

FIGURE 15: Comparison between the sum of the FRFs for the case of radial excitation and response measurement in the same direction, in two different radial planes $(x-z$ and $y-z)$.

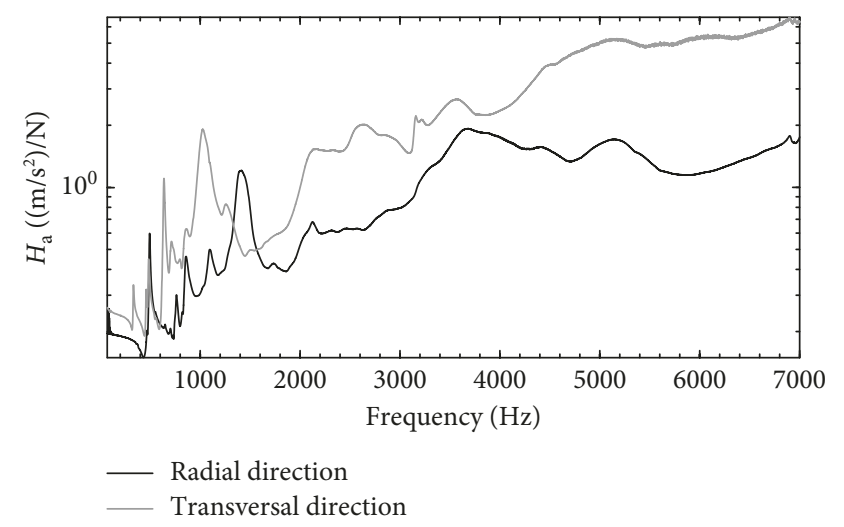

FIGURE 16: Sum of the FRFs for the two excitation references on the stator.

natural frequencies corresponding to the radial modal shapes are more sensitive to the shear modulus in the same plane. The Poisson coefficient did not show a significant influence on the reference frequencies.

Some numerical modal shapes of the winding are shown in Figures 17(a)-17(h) and resemble those identified experimentally. The winding twists shown in Figures 17(d), $17(\mathrm{~g})-17(\mathrm{i})$ were also visualized in the experimental trials but were not well defined. Virtual modal forms not identified experimentally can also appear in the numerical model but present less participation in the dynamic response, which in this case is adequate (Figures 18 and 19).

In order to reduce the number of degrees of freedom of the complete model, the simplified model that considers only the effect of the winding contour condition on the stator teeth was adjusted (Figure 5(b)). The correlation between the natural frequencies and the numerical and experimental modal shapes of the simplified model is shown in Table 6. The overall divergence between the natural frequencies is $8.6 \%$, and the mean deviation is $3.0 \%$, with a maximum deviation of $-6.8 \%$ and a minimum of $0.8 \%$. The corresponding MAC values are also shown in Table 6, with an average magnitude of $66.0 \%$ (maximum of $83.5 \%$ and minimum of $59.1 \%$ ). The result of the MAC calculation for this model of the stator was very close to the result of the first model, and for this reason, only one result was exposed. The five modal shapes and natural frequencies used in the fitting of both models are summarized in Figure 20, with emphasis on the experimental reference on the right. Despite the experimental limitations that can interfere in the quality of the modal reference parameters obtained, the adjustment is considered satisfactory.

Furthermore, there are experimental difficulties associated with the lack of feedback of excitation from the shaker in order to minimize the effects of nonlinearities and mass and accelerometer fixation on the attainment of modal parameters [35]. In addition, it is recommended that the clamping area of the triaxial accelerometers be the smallest possible to obtain a better definition of the location and accuracy of the measurement results. This is a factor that could greatly improve the results presented.

Following the same procedure described for the complete model, the same properties of the laminated disk were maintained in the $x-y$ plane (radial). The remainder of the properties was adjusted, maintaining the division of the outer part of the laminated disks volume and the inner part, which corresponds to the region of the teeth of the magnetic core (Figure 5(b)). The range of property constraints is shown in Table 3, and the result of the fitting can be seen in Table 5 . 


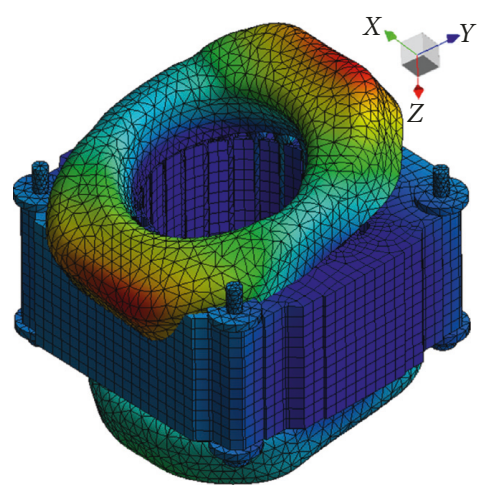

(a)

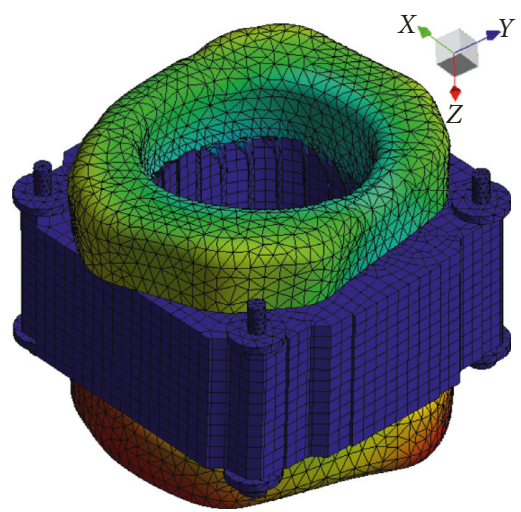

(d)

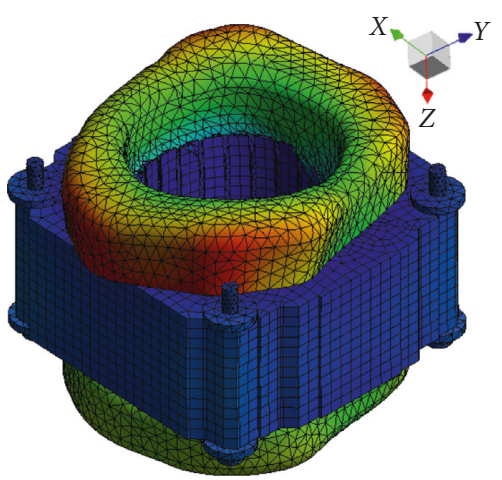

(g)

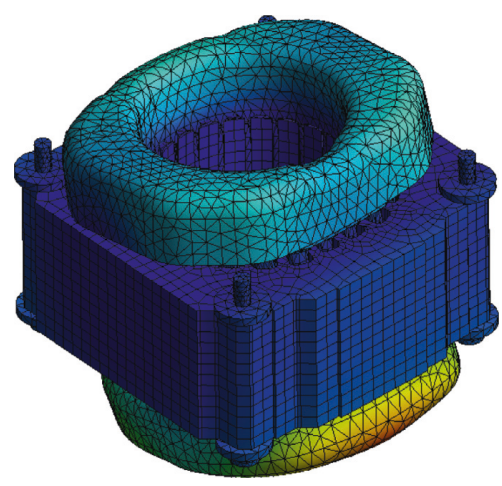

(b)

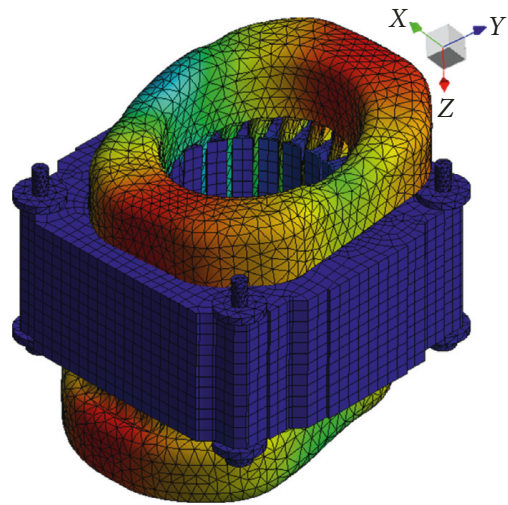

(e)

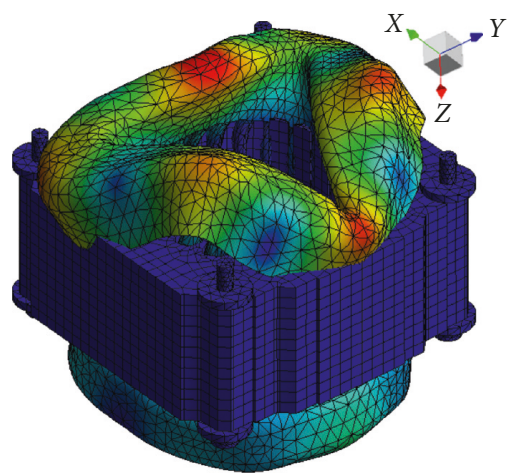

(h)

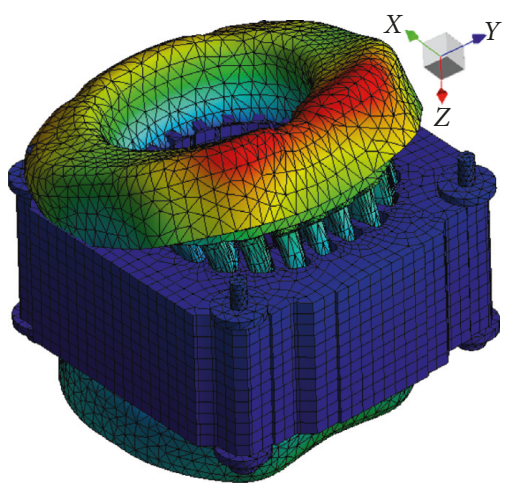

(c)

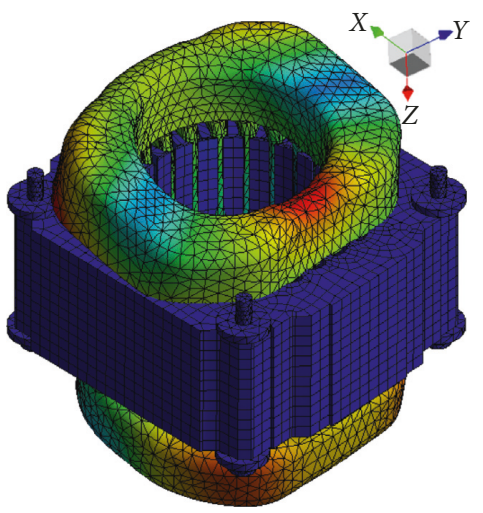

(f)

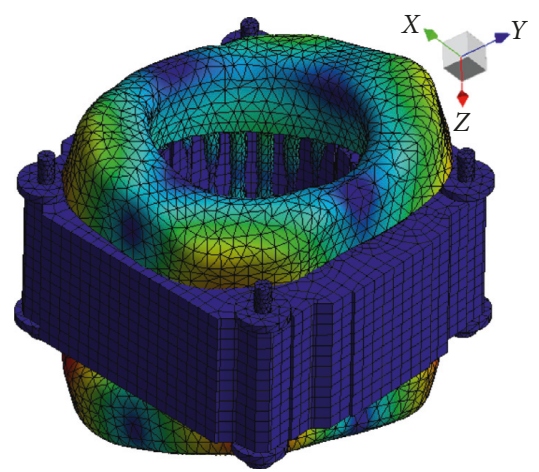

(i)

FIGURE 17: Modal shapes of the winding in the complete model $\left(300\right.$ to $900 \mathrm{~Hz}$ band): (a) $\omega^{\mathrm{N}}: 381.9 \mathrm{~Hz}$; (b) $\omega^{\mathrm{N}}: 422.4 \mathrm{~Hz}$; (c) $\omega^{\mathrm{N}}$ : $457.5 \mathrm{~Hz}$; (d) $\omega^{\mathrm{N}}$ : $605.0 \mathrm{~Hz}$; (e) $\omega^{\mathrm{N}}: 620.1 \mathrm{~Hz}$; (f) $\omega^{\mathrm{N}}: 658.2 \mathrm{~Hz}$; (g) $\omega^{\mathrm{N}}: 662.4 \mathrm{~Hz}$; (h) $\omega^{\mathrm{N}}: 752.0 \mathrm{~Hz}$; (i) $\omega^{\mathrm{N}}: 851.6 \mathrm{~Hz}$.

TABLE 3: Restriction of the interval of the properties.

\begin{tabular}{lcc}
\hline Properties & Restricted intervals (complete stator model) & Restricted intervals (simplified stator model) \\
\hline$\rho$ & 7560 (fixed) & $\begin{array}{c}\text { External: } 7560 \text { (fixed) } \\
\text { Internal: } 18000 \text { (fixed) } \\
\text { External: } 211 \text { (fixed) } \\
\text { Internal: } 290 \text { to } 340\end{array}$ \\
$E_{x}(\mathrm{GPa})$ & 211 (fixed) & External: 211 (fixed) \\
$E_{y}(\mathrm{GPa})$ & 211 (fixed) & Internal: 290 to 340 \\
$E_{z}(\mathrm{GPa})$ & 3 to 6 & 3 to 9 \\
$v_{x y}$ & 0.3 (fixed) & 0.3 (fixed) \\
$v_{y z}$ & 0.01 to 0.14 & 0.01 to 0.14 \\
$v_{x z}(\mathrm{GPa})$ & 0.01 to 0.14 & 0.01 to 0.14 \\
$G_{x y}(\mathrm{GPa})$ & 60 to 100 & 130 to 145 \\
$G_{y z}(\mathrm{GPa})$ & 0.3 to 0.6 & 0.3 to 0.6 \\
\hline
\end{tabular}


TABLE 4: Correlation between the numerical and experimental natural frequencies, for the stator model with the equivalent volume of the winding.

\begin{tabular}{lccc}
\hline Order & $\omega^{\mathrm{E}}(\mathrm{Hz})$ & $\omega^{\mathrm{N}}(\mathrm{Hz})$ & $\Delta \omega_{\mathrm{n}}(\%)$ \\
\hline 1 & 1084.0 & 1024.1 & -5.5 \\
2 & 1477.3 & 1543.7 & 4.5 \\
3 & 3621.4 & 3582.8 & -1.1 \\
4 & 3848.4 & 3884.4 & 0.9 \\
5 & 5129.3 & 4990.1 & -2.7 \\
\hline Average (\%) & & & 2.9 \\
$\ell_{\omega}(\%)$ & & & 7.8 \\
\hline
\end{tabular}

TABLE 5: Orthotropic and isotropic properties adjusted for the equivalent volume of the disks and the winding, for the complete model. Orthotropic properties adjusted for the equivalent volume of the disks for the stator model with absence of winding $(0 \mathrm{to} 10 \mathrm{kHz})$.

\begin{tabular}{|c|c|c|c|c|}
\hline \multirow{2}{*}{ Properties } & \multicolumn{2}{|c|}{ Complete stator model } & \multicolumn{2}{|c|}{ Stator model with absence of winding } \\
\hline & Set of laminated disks & Winding & Outer region to the teeth & Region of teeth \\
\hline$\rho$ & 7560 & 2676 & 7560 & 18000 \\
\hline$E_{x}(\mathrm{GPa})$ & 211 & 0.11 & 211 & 335 \\
\hline$E_{y}(\mathrm{GPa})$ & 211 & 0.11 & 211 & 335 \\
\hline$E_{z}(\mathrm{GPa})$ & 4.80 & 0.11 & 6.1 & 6.5 \\
\hline$\nu_{x y}$ & 0.3 & 0.09 & 0.3 & 0.3 \\
\hline$v_{y z}$ & 0.11 & 0.09 & 0.09 & 0.09 \\
\hline & 0.11 & 0.09 & 0.09 & 0.09 \\
\hline$G_{x y}(\mathrm{GPa})$ & 80 & 0.05046 & 143 & 143 \\
\hline$G_{y z}^{x y}(\mathrm{GPa})$ & 0.33 & 0.05046 & 0.49 & 0.54 \\
\hline$G_{x z}^{y z}(\mathrm{GPa})$ & 0.33 & 0.05046 & 0.49 & 0.54 \\
\hline$\eta_{\mathrm{eq}}$ & 0.1 & 0.015 & 0.06 & 0.06 \\
\hline
\end{tabular}

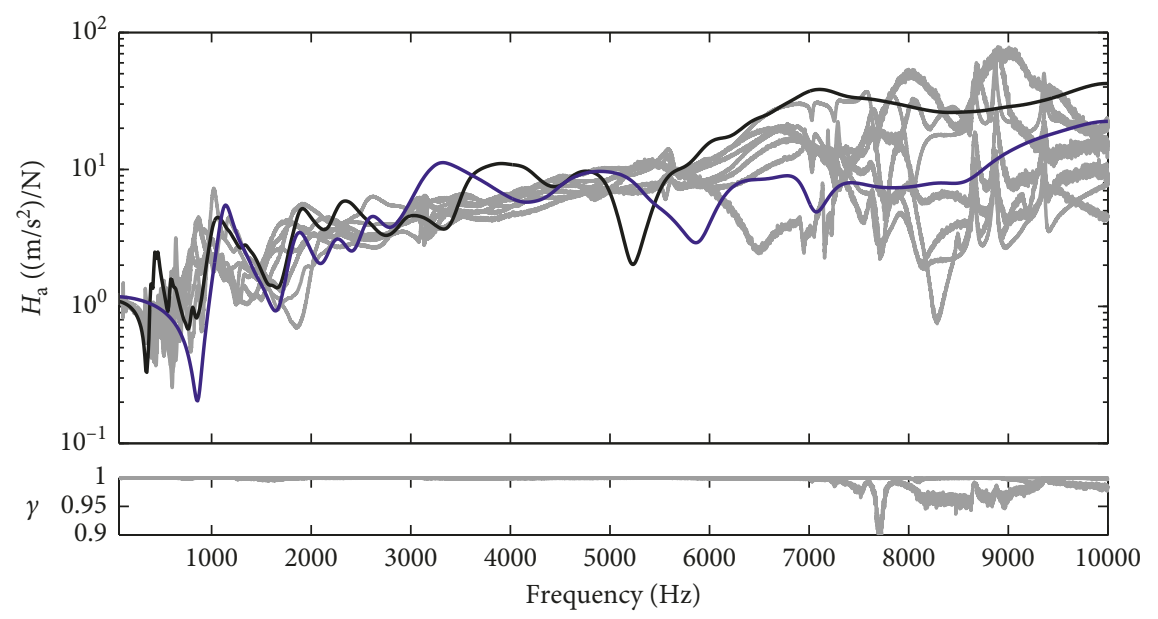

FIGURE 18: Comparison between the numerical (lines in black and blue) and experimental (lines in gray) FRF values for transversal excitation ( $z$ direction) and response measurement at point E1 ( $z$ direction).

The set of properties determined (Table 5) is consistent with previous studies in which the laminated stators were investigated. Although the models studied by Wang and Lai [4], Millithaler et al. [6], and Millithaler [21] are geometrically different, it was found that the modulus of elasticity in the radial direction is usually greater than the same parameter in the axial direction. Similarly, in general, the shear modulus and Poisson coefficient in the radial plane are larger compared to the same parameters in the two orthogonal directions.
7.4. Comparison of Results. The main difference between the two adjusted models is the presence of the main modal forms of the winding in the 300 to $900 \mathrm{~Hz}$ band. The computational solution is faster for the simplified model, which does not consider the coupling and winding vibration modes.

For frequencies higher than $900 \mathrm{~Hz}$, the physical presence of the winding can be neglected, since the dynamic behavior is very close to that of the simplified model. The absence of the winding significantly reduces the modal density of the part, due to the exclusion of modes located at 


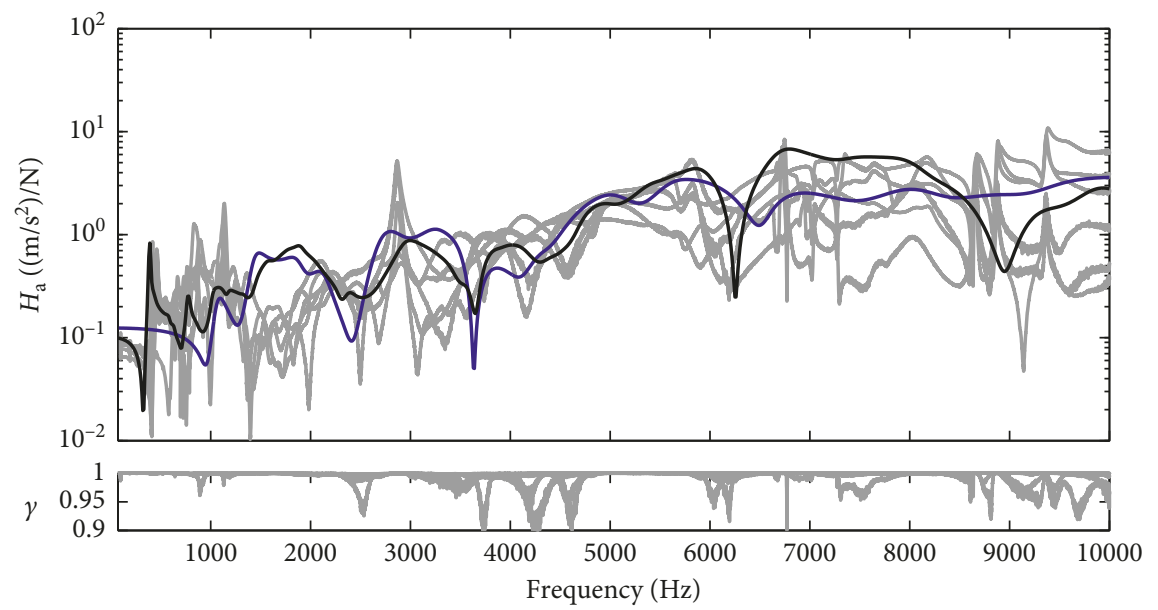

FIgURE 19: Comparison between the numerical (lines in black and blue) and experimental (lines in gray) FRF values for radial excitation ( $y$ direction) and response measurement at point E1 ( $z$ direction).

TABLE 6: Correlation between the natural frequencies and modal numerical and experimental shapes for the stator model without the physical presence of the winding.

\begin{tabular}{lcccc}
\hline Order & $\omega^{\mathrm{E}}(\mathrm{Hz})$ & $\omega^{\mathrm{N}}(\mathrm{Hz})$ & $\Delta \omega_{\mathrm{n}}(\%)$ & MAC $(\%)$ \\
\hline 1 & 1084.0 & 1136.9 & 4.9 & 83.5 \\
2 & 1477.3 & 1489.8 & 0.8 & 62.4 \\
3 & 3621.4 & 3656.5 & 1.0 & 63.8 \\
4 & 3848.4 & 3796.2 & -1.4 & 61.3 \\
5 & 5129.3 & 4780.0 & -6.8 & 59.1 \\
\hline Average (\%) & & & 3.0 & 66.0 \\
$\ell_{\omega}(\%)$ & & & 8.6 & \\
\hline
\end{tabular}

frequencies above $900 \mathrm{~Hz}$. Due to the difficulty associated with modeling a set of copper wires, this approximation by a homogeneous isotropic material proved to be representative.

For the purpose of comparison with the modal shapes of the laminated disk (Figure 12), there are modal shapes of the stator shown in Figure 21 (in the same sequence), obtained numerically for the simplified stator model. Clearly, it can be seen that the modal shapes of the stator have characteristics similar to the modal shapes of a single laminated disk.

Point E1 in Figure 5(b) was used to obtain a response and two reference points (transversal and radial) for matching between numerical and experimental FRFs. These comparisons can be seen in Figures 18 and 19, in which the FRFs in black and blue are the numerical values, where the black line represents the complete model and the blue line corresponds to the simplified model of the stator. The experimental FRFs in gray relate to the samples of seven stators. The FRFs present good correlations, and the numerical results are within the range of experimental variability obtained. In this case, a constant damping factor was used (Table 5). However, optimized modal damping factors can be specified for the calibration of response levels, in concordance with the experimental results.

As mentioned above, due to the absence of the physical volume of the winding, the simplified numerical model loses accuracy in the frequency range between 300 and $900 \mathrm{~Hz}$. Both numerical models show low sensitivity in representing the physical process of detachment of the laminated disks, particularly above $7 \mathrm{kHz}$.

On comparing the FRFs shown in gray in the graphs, it can be noted that the experimental variability is accentuated. Considering that the properties of the laminated disks vary little from one stator to the other, the observed variability between the stators is mainly associated with the uncertainties of the tightening torque of the screws and the winding, that is, the stiffness oscillations of fixation, of mass and, therefore, of damping. For the set of eight stators evaluated, the largest mass deviation in relation to the average mass was $27.0 \mathrm{~g}$, associated with the winding. As the mass difference between the stators is relatively small, it is concluded that the variability between stators has the predominant influence of stiffness and damping.

\section{Conclusions}

Satisfactory numerical representations were obtained through the application of the homogenization method for the two proposed numerical models, with addition of the prestress effect of the screws and the connection between the components. For all property settings, the average deviation between the numerical and experimental natural frequencies was equal to or less than $3.0 \%$. These numerical models can be used in many practical applications with relatively low computational cost. However, depending on the purpose of the study, a more detailed representation of the connection properties and the physical phenomenon involved may be required, resulting in a considerable increase in the number of degrees of freedom of the models.

The simplified numerical model of the laminated stator presented limitations of representativeness in the frequency range between 300 and $900 \mathrm{~Hz}$ due to the absence of the modal shapes of the winding. Although diverging from the physical reality, properties such as the modulus of elasticity and density, measured for the region of the teeth in the simplified model, impart a dynamic behavior close to those of the complete model and the real component. 

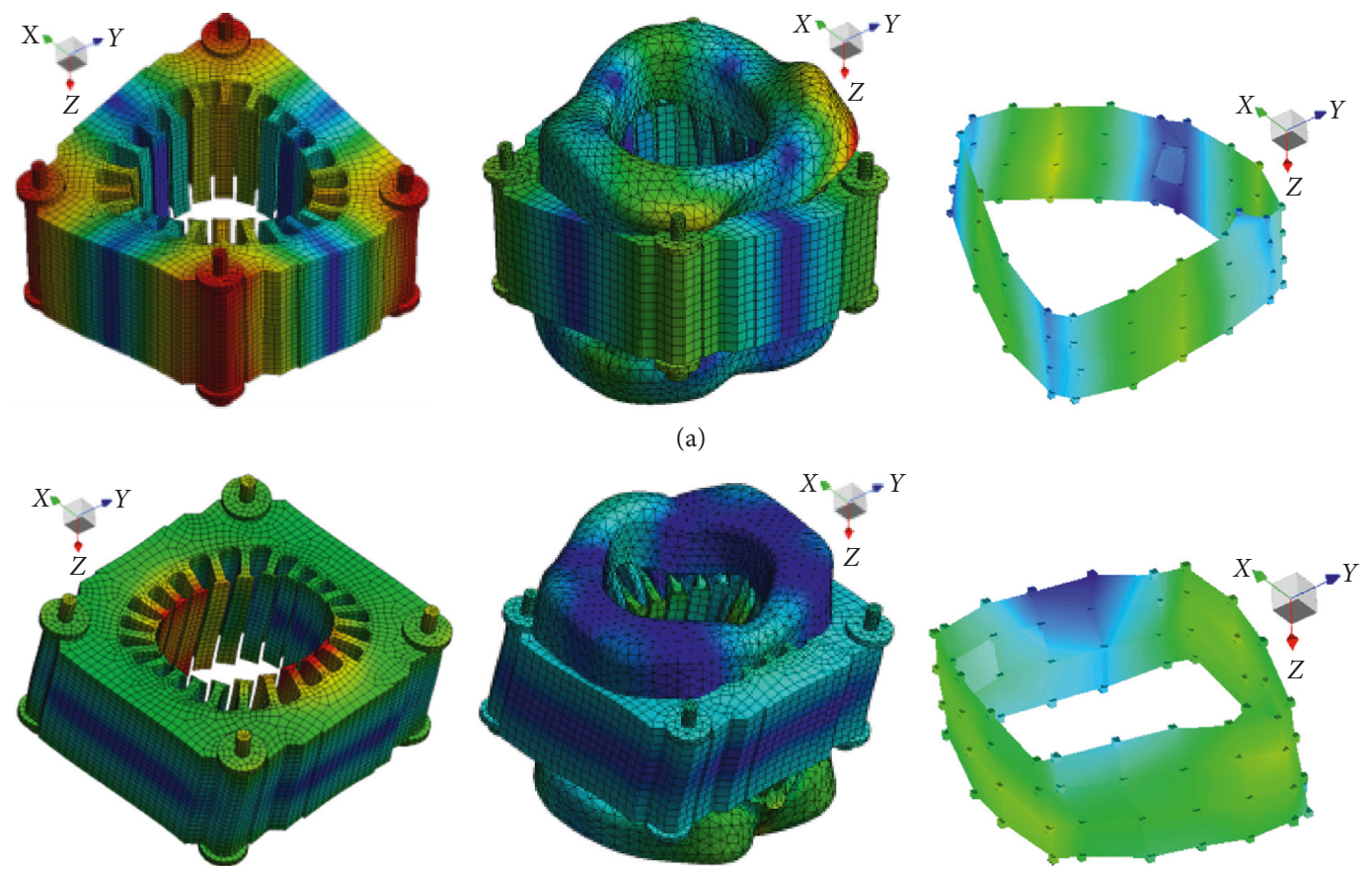

(b)
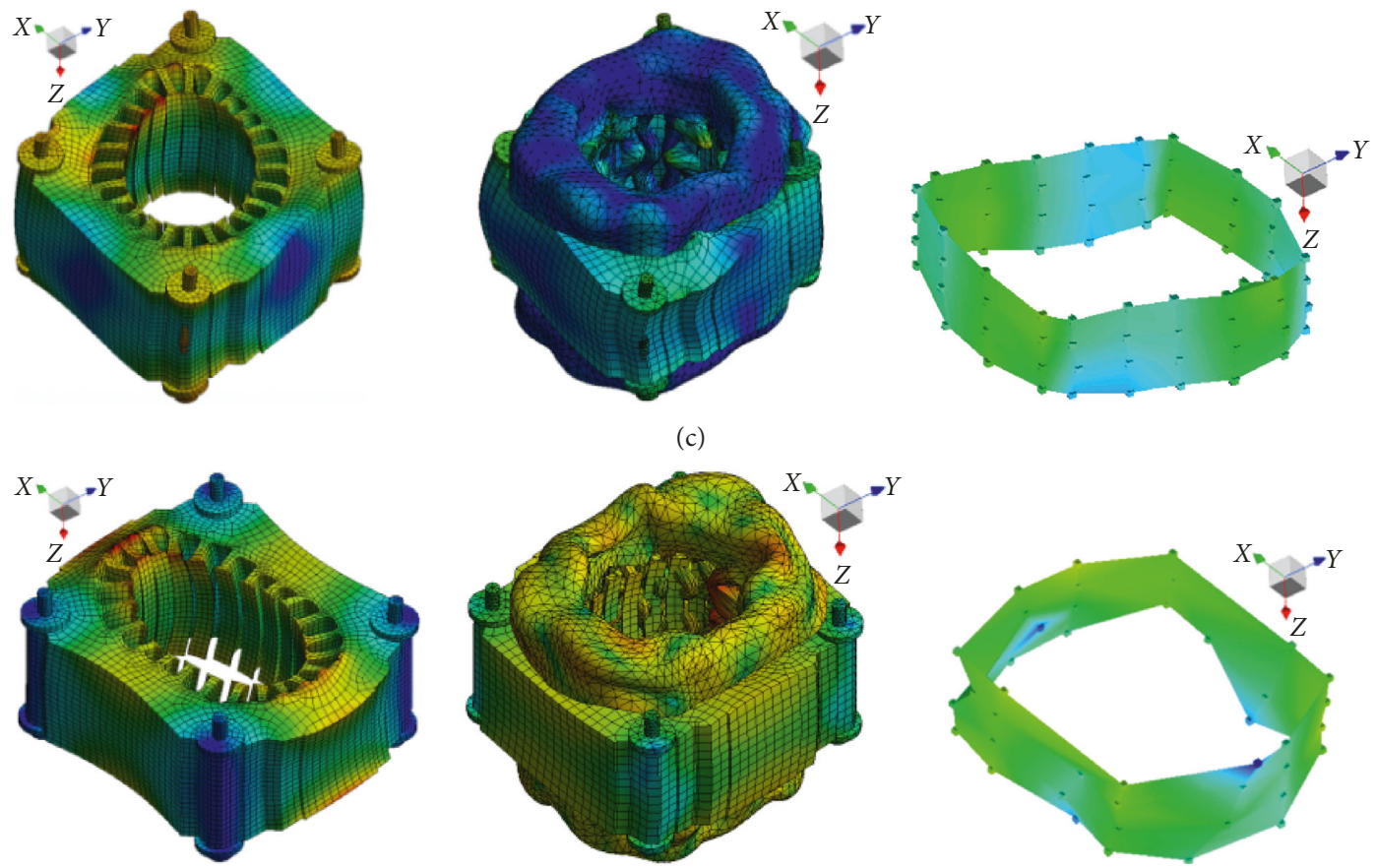

(d)

Figure 20: Continued. 

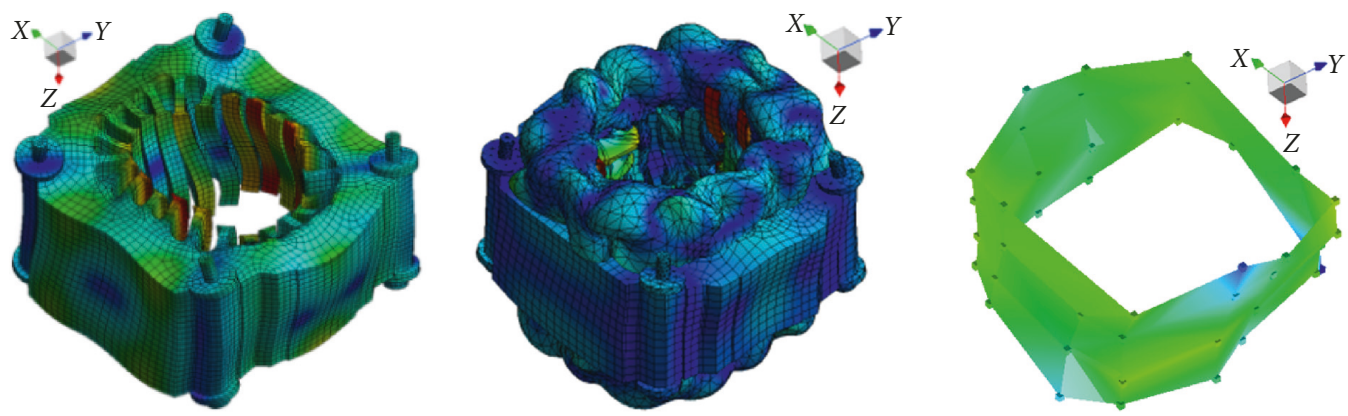

(e)

FiguRE 20: Numerical and experimental modal shapes of the stator adopted for the fitting model: (a) $\omega^{\mathrm{N}}: 1136.9 \mathrm{~Hz} ; \omega^{\mathrm{N}}: 1124.1 \mathrm{~Hz} ; \omega^{\mathrm{E}}$ : $1084.0 \mathrm{~Hz}$. (b) $\omega^{\mathrm{N}}: 1489.8 \mathrm{~Hz} ; \omega^{\mathrm{N}}: 1543.7 \mathrm{~Hz} ; \omega^{\mathrm{E}}: 1477.3 \mathrm{~Hz}$. (c) $\omega^{\mathrm{N}}: 3656.5 \mathrm{~Hz} ; \omega^{\mathrm{N}}: 3582.8 \mathrm{~Hz} ; \omega^{\mathrm{E}}: 3621.4 \mathrm{~Hz} .(\mathrm{d}) \omega^{\mathrm{N}}: 3796.2 \mathrm{~Hz} ; \omega^{\mathrm{N}}$ : $3884.4 \mathrm{~Hz} ; \omega^{\mathrm{E}}: 3848.4 \mathrm{~Hz}$. (e) $\omega^{\mathrm{N}}: 4780.0 \mathrm{~Hz} ; \omega^{\mathrm{N}}: 4990.1 \mathrm{~Hz} ; \omega^{\mathrm{E}}: 5129.3 \mathrm{~Hz}$.

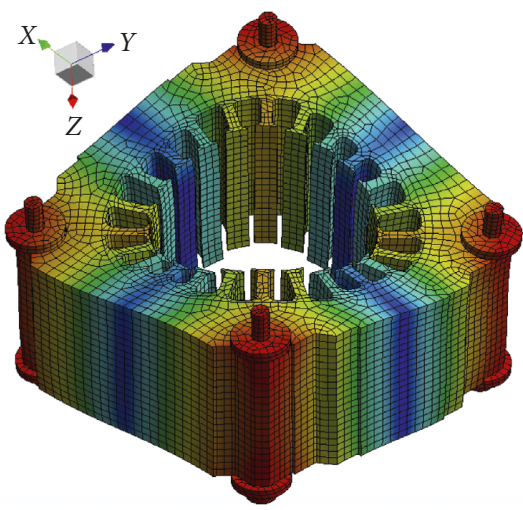

(a)

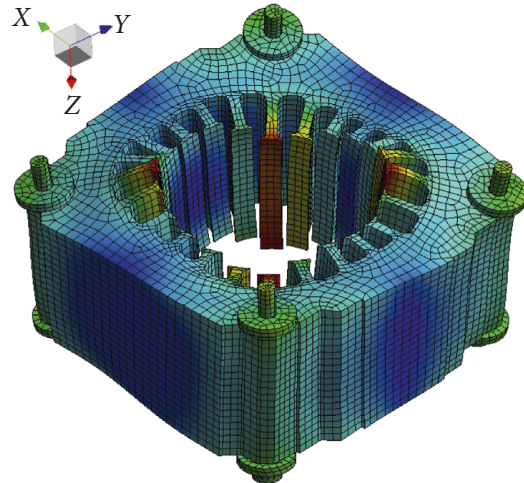

(b)

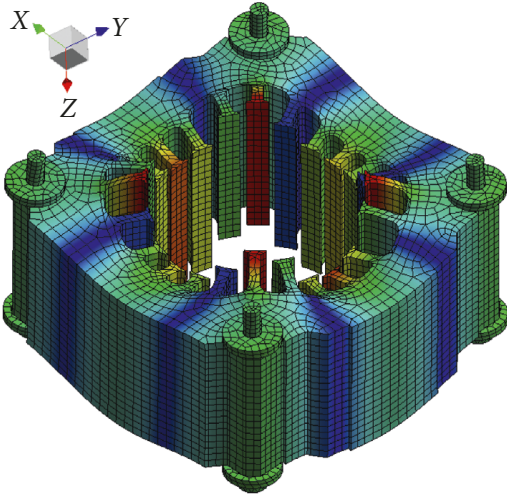

(c)

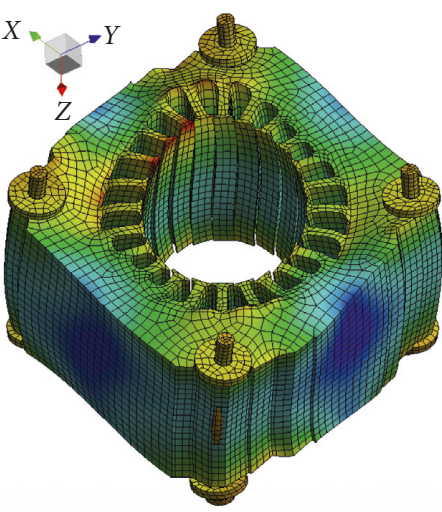

(d)

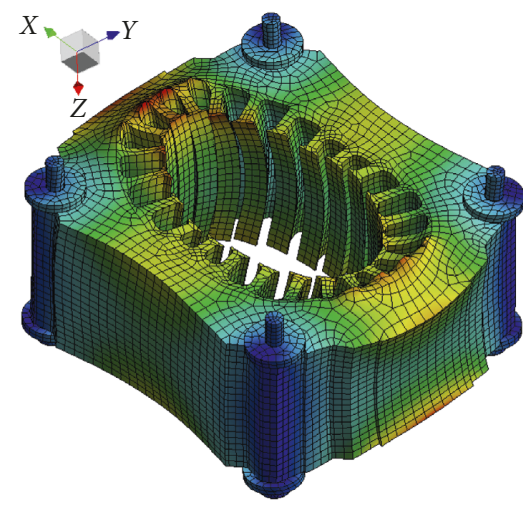

(e)

Figure 21: Numerical modal shapes of the stator model with absence of winding: (a) $\omega^{\mathrm{N}}$ : $1136.9 \mathrm{~Hz}$; (b) $\omega^{\mathrm{N}}$ : $2619.7 \mathrm{~Hz}$; (c) $\omega^{\mathrm{N}}$ : $2267.3 \mathrm{~Hz}$; (d) $\omega^{\mathrm{N}}: 3656.5 \mathrm{~Hz} ;(\mathrm{e}) \omega^{\mathrm{N}}: 3796.2 \mathrm{~Hz}$.

The two numerical models do not accurately describe the discontinuities of the laminated disks, particularly at frequencies above $7 \mathrm{kHz}$. It should be noted that contour condition effects interfered in the experimental process of obtaining the modal parameters, mainly due to the complexity of the component tested. The damping can also be optimized, as a function of the frequency, to obtain a better correlation between the numerical and experimental FRFs.

The prestress effect applied to the stator screws proved to be important to better characterize the modal forms of numerical models and to change the local stiffness around the connections due to the stress-stiffening effect. Modal synthesis performed with the commercial Ansys ${ }^{\circledR}$ software was found to be adequate, enabling computational vibroacoustic analysis.

The presented method for the identification of properties is an alternative in relation to the rare existing approaches for this application. Its implementation is practical and efficient and depends on the user experience. It provides suitable representations of predominantly radial and transverse modal shapes with the addition of boundary conditions, such as fastening and winding elements. 


\section{Data Availability}

The data that support the findings of this study are openly available at https://repositorio.ufsc.br/xmlui/handle/123456789/ 180407.

\section{Conflicts of Interest}

The authors declare that they have no conflicts of interest.

\section{Acknowledgments}

The first author received financial support from the Brazilian governmental agency CNPq, which is gratefully acknowledged.

\section{References}

[1] L. K. C. R. Gomes, "Análise dinâmica do estator de um motor elétrico," Master's thesis, Universidade Federal de Santa Catarina, Florianópolis, Brazil, 2014.

[2] J.-B. Dupont, P. Bouvet, and L. Humbert, "Vibroacoustic simulation of an electric motor: methodology and focus on the structural FEM representativity," in Proceedings of the 2012 XXth International Conference on Electrical Machines, Institute of Electrical and Electronics Engineers (IEEE), Marseille, France, September 2012.

[3] G. Myrria Neto, Análise da contribuição das forças magnéticas durante o comportamento vibroacústico do compressor alternativo, Ph.D. thesis, Universidade Federal de Santa Catarina, Florianópolis, Brazil, 2015.

[4] C. Wang and J. C. S. Lai, "Vibration analysis of an induction motor," Journal of Sound and Vibration, vol. 224, no. 4, pp. 733-756, 1999.

[5] A. L. Kalamkarov, I. V. Andrianov, and V. V. Danishevs'kyy, "Asymptotic homogenization of composite materials and structures," Applied Mechanics Reviews, vol. 62, no. 3, article 030802, 2009.

[6] P. Millithaler, É. Sadoulet-Reboul, M. Ouisse, J.-B. Dupont, and N. Bouhaddi, "Structural dynamics of electric machine stators: Modelling guidelines and identification of threedimensional equivalent material properties for multilayered orthotropic laminates," Journal of Sound and Vibration, vol. 348, pp. 185-205, 2015.

[7] D. Begis, A. Bestagno, G. Duvaut, A. Hassim, and M. Nuc, A New Method of Computing Global Elastic Moduli for Composite Materials, Vol. 195, Rapports de Recherche-Institut National de Recherche en Informatique et en Automatique, Rocquencourt, France, 1983.

[8] A. Holmbom, L. E. Persson, and N. Svanstedt, "A homogenization procedure for computing effective moduli and microstresses in elastic composite materials," Composites Engineering, vol. 2, no. 4, pp. 249-259, 1992.

[9] J. G. Vargas, "Análise das fontes de ruído de uma lavadoura de roupa," Master's thesis, Universidade Federal de Santa Catarina, Florianópolis, Brazil, 2017.

[10] W. Cai, P. Pillay, and Z. Tang, "Impact of stator windings and end-bells on resonant frequencies and mode shapes of switched reluctance motors," IEEE Transactions on Industry Applications, vol. 38, no. 4, pp. 1027-1036, 2002.

[11] D. Franck, M. van der Giet, and K. Hameyer, "Simulation of acoustic radiation of an AC servo drive," COMPEL-the International Journal for Computation and Mathematics in
Electrical and Electronic Engineering, vol. 29, no. 4, pp. 1060-1069, 2010.

[12] R. S. Girgis and S. P. Verma, "Resonant frequencies and vibration behavior of stators of electrical machines as affected by teeth, windings, frame and laminations," IEEE Transactions on Power Apparatus and Systems, vol. PAS-98, no. 4, pp. 1446-1455, 1978.

[13] S. P. Verma and A. Balan, "Experimental investigations on the stators of electrical machines in relation to vibration and noise problems," IEE Proceedings-Electric Power Applications, vol. 145 , no. 5 , p. $455,1998$.

[14] P. W. Chung, K. K. Tamma, and R. R. Namburu, "Asymptotic expansion homogenization for heterogeneous media: computational issues and applications," Composites Part A: Applied Science and Manufacturing, vol. 32, no. 9, pp. 1291-1301, 2001.

[15] J. C. Marcon, "Análise do comportamento dinâmico do conjunto bloco e motor elétrico de um compressor hermético," M.Sc. thesis, Universidade Federal de Santa Catarina, Florianópolis, Brazil, 2016 https://repositorio.ufsc. br/xmlui/handle/123456789/1456789/180407.

[16] J. C. Marcon, A. Lenzi, and O. M. Silva, "Identification of three-dimensional equivalent material properties for laminated disks pack of electric machine stators with stressstiffening effect," in Proceedings of the 24th ABCM International Congress of Mechanical Engineering, vol. 24, ABCM, Curitiba, Brazil, December 2017.

[17] J. C. Marcon, A. Lenzi, O. M. Silva, and W. S. Sousa, "Structural characterization of the block and stator group of a hermetic compressor," in Proceedings of the XVII International Symposium on Dynamic Problems of Mechanics, vol. 17, ABCM, Rio de Janeiro, Brazil, July 2018.

[18] J. E. Mothershead and M. I. Friswell, "Model updating in structural dynamics: a survey," Journal of Sound and Vibration, vol. 167, no. 2, pp. 347-375, 1993.

[19] R. J. Allemang and D. L. Brown, "Correlation coefficient for modal vector analysis," in Proceedings of the 1st International Modal Analysis Conference, pp. 110-116, Orlando, FL, USA, November 1982.

[20] R. J. Allemang, "The modal assurance criterion (MAC): twenty years of use and abuse," Journal of Sound and Vibration, vol. 37, no. 8, pp. 14-23, 2003.

[21] P. Millithaler, Dynamic behaviour of electric machine stators: modelling guidelines for efficient finite-element simulations and design specifications for noise reduction, Ph.D. thesis, Université de Franche-Comté, Besançon, France, 2015.

[22] J. Dascotte and J. Strobbe, "Updating finite element models using FRF correlation functions," in Proceedings of the 17th International Modal Analysis Conference, pp. 1169-1174, Kissimmee, FL, USA, February 1999.

[23] M. I. Friswell, "The adjustment of structural parameters using a minimum variance estimator," Mechanical Systems and Signal Processing, vol. 3, no. 2, pp. 143-155, 1989.

[24] M. I. Friswell and J. E. Mottershead, Finite Element Model Updating in Structural Dynamics, Kluwer Academic Publishers Incorporates, Dordrecht, Netherlands, 1995.

[25] P. O. Larsson and P. Sas, "Model updating based on forced vibration testing using numerically stable formulations," in Proceedings of the 10th International Modal Analysis Conference, San Diego, CA, USA, February 1992.

[26] R. M. Lin and D. J. Ewins, "Model updating using FRF data," in Proceedings of the 13th International Seminar on Modal Analysis, Leuven, Belgium, November 1990. 
[27] M. Link, "Updating analytical models by using local and global parameters and relaxed optimisation requirements," Mechanical Systems and Signal Processing, vol. 12, no. 1, pp. 7-22, 1998.

[28] C. Zang, H. Grafe, and M. Imregun, "Frequency-domain criteria for correlating and updating dynamic finite element models," Mechanical Systems and Signal Processing, vol. 15, no. 1, pp. 139-155, 2001.

[29] L. Wei and Y. Yuying, "Multi-objective optimization of sheet metal forming process using pareto-based genetic algorithm," Journal of Materials Processing Technology, vol. 208, no. 1-3, pp. 499-506, 2008.

[30] K. Deb, Multi-Objective Optimization Using Evolutionary Algorithms, vol. 1, Wiley, New York, NY, USA, 2001, ISBN 047187339X.

[31] W. K. Mashwani, "Hybrid multiobjective evolutionary algorithms: a survey of the state-of-the-art," IJCSI International Journal of Computer Science Issues, vol. 8, no. 6, 2011.

[32] K. Deb, A. Pratap, S. Agarwal, and T. Meyarivan, "A fast and elitist multiobjective genetic algorithm: NSGA-II," IEEE Transactions on Evolutionary Computation, vol. 6, no. 2, pp. 182-197, 2002.

[33] L. E. Malvern, Introduction to the Mechanics of a Continuous Medium, Vol. 1, Prentice-Hall, Englewood Cliffs, NJ, USA, 1969.

[34] E. B. Tadmor, R. E. Miller, and R. S. Elliott, Continuum Mechanics and Thermodynamics, Cambridge University Press, New York, NY, USA, 2012, ISBN 978-1-107-00826-7.

[35] G. L. Nessler and J. C. Deel, Excitation Control for Consistent Modal Parameters When Testing Nonlinear Structures, Society Automotive Engineers, Warrendale, PA, USA, 2003.

[36] S. P. Verma and R. S. Girgis, "Experimental verification of resonant frequencies and vibration behaviour of stators of electrical machines: part 1-models, experimental procedure and apparatus," IEE Proceedings B Electric Power Applications, vol. 128, no. 1, pp. 12-21, 1981.

[37] R. J. Craig, "A review of time domain and frequency domain component modal synthesis methods," International Journal of Analytical and Experimental Modal Analysis, vol. 2, no. 2, pp. 59-72, 1987.

[38] R. R. Craig and M. D. D. Bampton, "Coupling of substructures for dynamic analysis," AIAA Journal, vol. 6, no. 7, pp. 1313-1319, 1968.

[39] D. N. Herting, "A general purpose, multi-stage, component modal synthesis method," Finite Elements in Analysis and Design, vol. 1, no. 2, pp. 153-164, 1985.

[40] D. R. Martinez, T. Carne, D. Gregory, and A. Miller, "Combined experimental/analytical modeling using component mode synthesis," in Proceedings of the 25th Structures, Structural Dynamics and Materials Conference, pp. 140-152, Palm Springs, CA, USA, May 1984.

[41] H. Wang, "Experimental study of vibration behavior of laminated annular disks," Journal of the Acoustical Society of America, vol. 111, no. 4, pp. 1701-1708, 2002. 


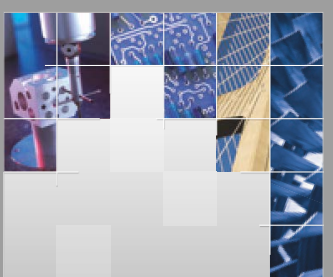

\section{Enfincering}
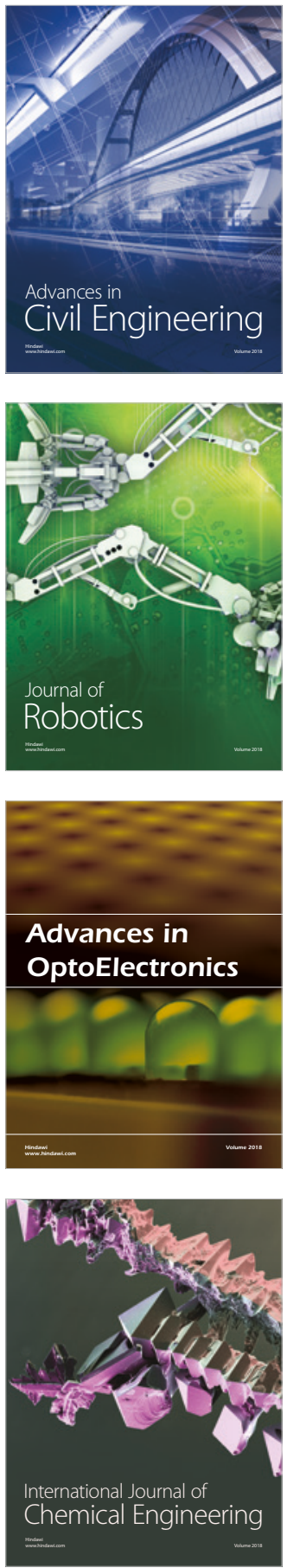

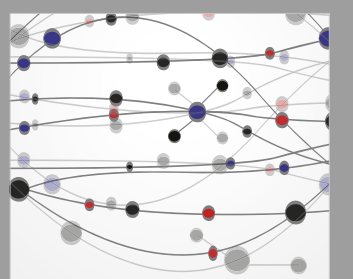

\section{Rotating \\ Machinery}

The Scientific World Journal

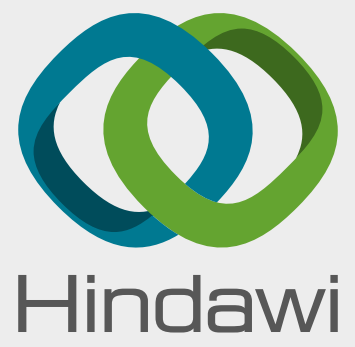

Submit your manuscripts at

www.hindawi.com
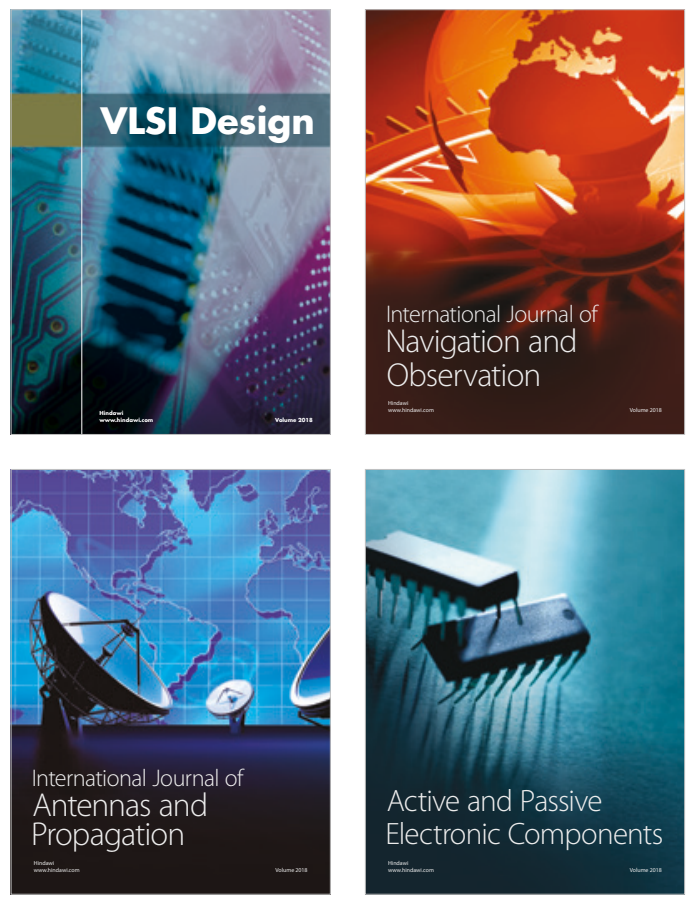
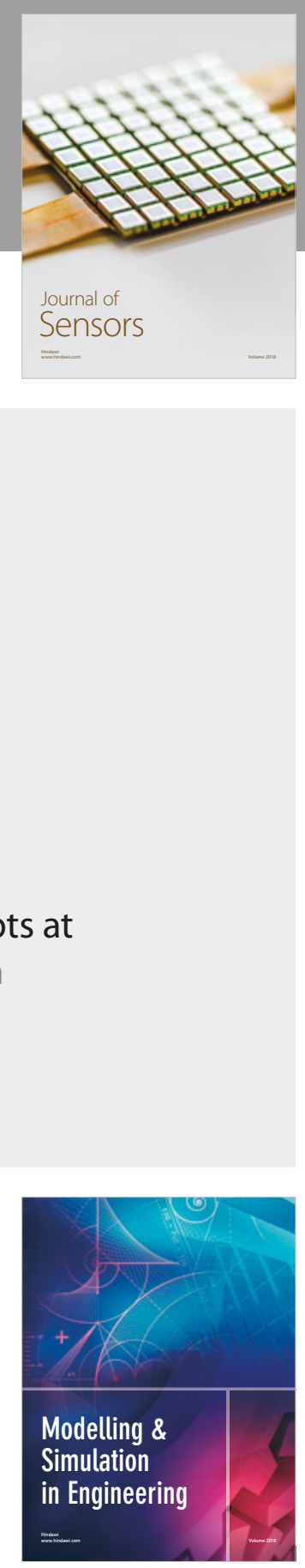

\section{Advances \\ Multimedia}
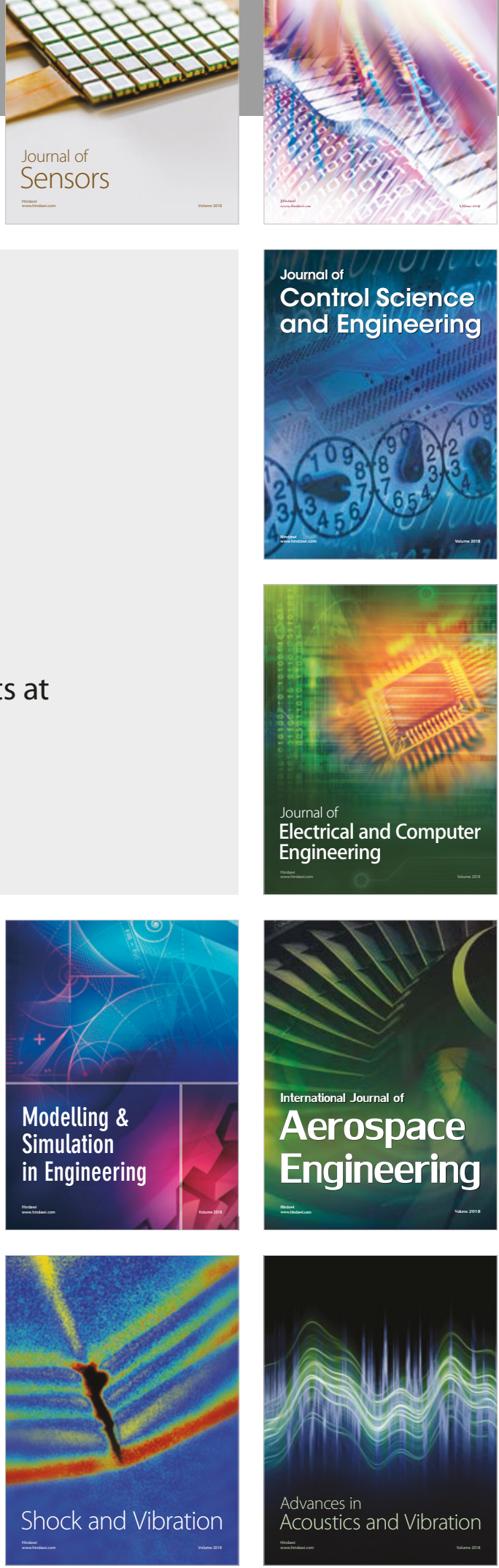